\title{
Assessment of potential heat flux overload of target and first wall components in Wendelstein 7-X finite-beta magnetic configurations and choice of locations for temperature monitoring
}

\author{
G. Bongiovi ${ }^{\mathrm{a} *}$, D. Böckenhoff ${ }^{\mathrm{b}}$, A. Carls ${ }^{\mathrm{b}}$, M. Endler ${ }^{\mathrm{b}}$, J. Fellinger ${ }^{\mathrm{b}}$, J. Geiger $^{\mathrm{b}}$, W7-X Team $^{2}$ \\ ${ }^{a}$ Karlsruhe Institute of Technology (KIT), Institute for Neutron Physics and Reactor Technology \\ (INR), Hermann-von-Helmholtz-Platz 1, 76344 Eggenstein-Leopoldshafen, GERMANY \\ ${ }^{b}$ Max-Planck-Institut für Plasmaphysik (IPP), Wendelsteinstraße 1, 17491 Greifswald, GERMANY
}

Within the framework of R\&D activities on the Wendelstein 7-X (W7-X) stellarator machine, the assessment of heat loads onto the plasma facing components (PFCs) is an important aspect. So far, W7$\mathrm{X}$ was operated in short pulses without water cooling of the PFCs. Presently, the device is being prepared for future operation phases with water cooling. The target plates, which receive the highest heat loads, are monitored by a thermography system. The rest of the first wall (heat shield) is not designed to receive convective particle loads, and it is in part poorly monitored by the infrared cameras. Recent studies have shown that for many plasma configurations there are locations on the heat shield which do receive significant convective heat flux. This is in particular true for the heat shields adjacent to the target plates (called baffles) and for configurations with finite plasma pressure, where the magnetic configuration is modified by plasma currents. On the other side, the heat flux limit to the baffle tiles had to be reduced from 0.50 to $0.25 \mathrm{MW} / \mathrm{m}^{2}$.

In this work an evaluation of the heat flux to targets and baffles in plasma configurations with finite plasma pressure is presented. To this end, Field Line Diffusion (FLD) calculations have been performed to obtain the heat load pattern distributions for the considered magnetic configurations. The results have been assessed statistically to achieve a measure of certainty in the prediction of an overload in a certain location. The possibility of overloads onto the baffles due to plasma radiation has also been investigated. The results of the entire analysis show that local temperature monitoring by thermocouples in a rather limited number of locations will be sufficient to avoid heat flux overloads of the baffles and heat shields in all magnetic configurations considered.

Keywords: Wendelstein 7-X (W7-X), overloads, baffle, divertor, finite-beta, field-line diffusion *corresponding author's email: gaetano.bongiovi @kit.edu

\section{Introduction}

Within the framework of the European roadmap to the realization of fusion energy [1], the construction and operation of the Wendelstein 7-X (W7-X) stellarator machine represents one of the big milestones. The W7-X is a large stellarator with superconducting coils, operated at the Greifswald site of the Max-Planck-Institut für Plasmaphysik [2]. The first goal of the W7-X operation has been to 
show the feasibility of building a superconducting modular stellarator with the required precision which has been successfully shown [3][4][5]. A second primary objective is to demonstrate the accessibility of plasma parameters close to those of a future Fusion Power Plant (FPP) [6][7], which is ongoing work [8][9]. The last goal will be to prove the possibility of high-power steady-state operation.

W7-X can be operated in different magnetic configurations, controlled by the currents in the different types of field coil [10]. Those configurations envisaged for high-power operation are characterised by a chain of natural magnetic islands at the plasma boundary. In any toroidal cross section, the magnetic flux surfaces in the island region form an $\mathrm{O}$ point in the centre of each island and an $\mathrm{X}$ point between two adjacent islands [11]. In the 3D view the corresponding $\mathrm{O}$ and $\mathrm{X}$ points of each cross section are connected by field lines closing upon themselves after a low number of toroidal revolutions. The islands are intersected by the target plates (island divertor concept) [9][12][13]. Following the typical five-fold toroidal symmetry and the up-down flip symmetry (stellarator symmetry), the targets are arranged in ten identical divertor units (Figure 1).

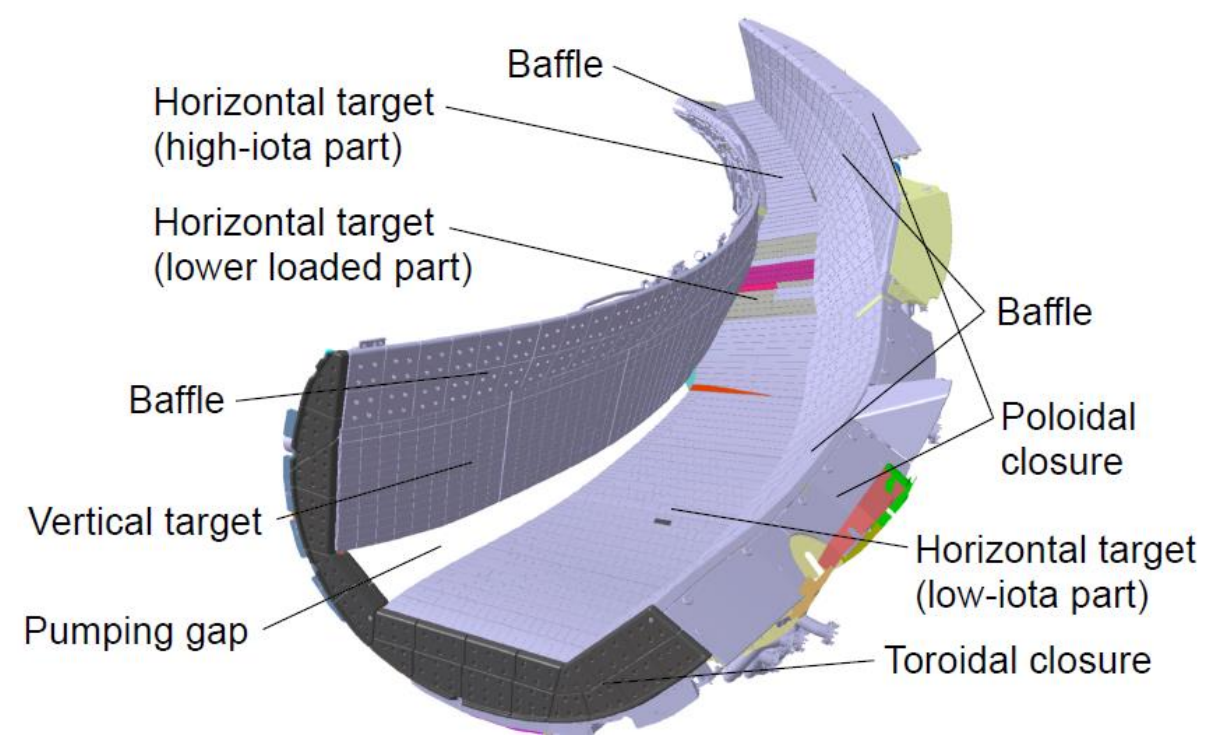

Figure 1. W7-X divertor unit.

So far, W7-X was operated with uncooled test divertor units (TDU) [14]. For future operation phases, a water-cooled high heat flux (HHF) divertor will be installed [15]. It is then planned to operate W7-X in steady-state discharges of up to $30 \mathrm{~min}$ with $10 \mathrm{MW}$ of heating power. Adjacent to the target plates, where lower heat loads are expected, so called baffles are installed (Figure 1). The remaining surface of the plasma vessel is covered partly by wall protection tiles of the same design as the baffles [16], partly by steel panels [17]. In the future stellarator FPPs, almost all the plasma vessel internal wall will be covered by breeding blanket modules [18][19][20][21] aimed at removing the thermal power generated by the fusion plasma, shielding the magnets from neutron and gamma radiation and ensuring the tritium breeding of the plant.

For high-power long-pulse operation of $\mathrm{W} 7-\mathrm{X}$, it is essential to protect the Plasma Facing Components (PFCs) listed above from heat loads exceeding the design specifications. This is 
particularly important for the baffles and targets, which are the most loaded PFCs because of the convective heat power deposited by charged particles. During the first divertor operation phase of W7$X$, baffle loads above the design values were derived from infrared (IR) camera images [22], presumably because anomalous transport perpendicular to the magnetic field is higher than assumed during the design of the PFCs. At the same time, refined thermomechanical analysis of the baffles indicated that the maximum thermal load to these components should be reduced [23]. Whereas the target plates and part of the baffles is well monitored by IR cameras (Figure 2), there are locations in which baffle or wall protection tiles cannot be observed.

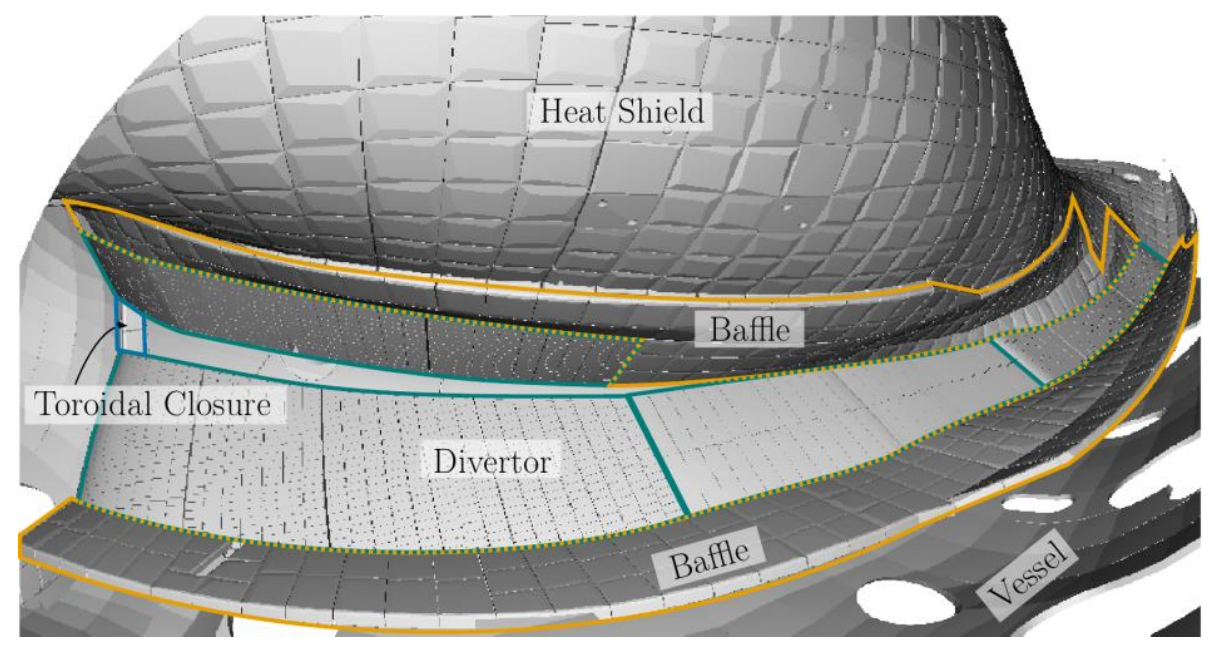

Figure 2. W7-X PFCs viewed by the IR camera standpoint [29].

It was therefore decided to install thermocouples in the heat sinks of selected baffle and wall protection tiles in order to avoid thermal overload to these components.

We are using field line diffusion (FLD) [24] to simulate the convective power load to PFCs. Whereas this has been done before mostly for the W7-X vacuum reference configurations [25] [26] and only for a few cases with finite plasma pressure, and with a focus on the target loads [27] [28], we shall here investigate configurations with finite plasma pressure. These are the so-called finite- $\beta$ configurations, where $\beta=p /\left(B^{2} /\left(2 \mu_{0}\right)\right.$ is the ratio between plasma pressure and magnetic pressure. The magnetohydrodynamic equilibria with finite plasma pressure in a toroidally confined plasma are radially shifted toward the torus outboard side relative to the vacuum flux surfaces, such that we expect potential overload to occur on baffle tiles on the torus outboard side.

In this paper, we shall describe the methodology adopted to select a limited number of baffle positions for temperature monitoring. The basic philosophy is described in section 2, together with the approach to model the heat load onto PFCs for some magnetic configurations and to assess its statistical significance. Section 3 reports the main outcomes of the overload calculations whereas in section 4 we present the locations selected for temperature monitoring. Lastly, conclusions are given in section 5 and a complete overview of the overload calculations carried out is reported in the Appendix.

\section{Methodology adopted}




\subsection{Calculation of thermal loads to wall components}

In order to calculate the thermal loads onto W7-X target and wall components for a certain magnetic configuration, the following procedure was used. Whereas for a vacuum configuration (i. e., the changes in magnetic field due to plasma currents are negligible) the magnetic field inside the W7-X plasma vessel was calculated from the currents in the field coils (represented as filaments), for a finite- $\beta$ plasma the magnetic field of a magnetohydrodynamic equilibrium was calculated by the VMEC [30] and EXTENDER [31] codes. After that, the FLD technique was used in order to obtain the thermal loads to the wall components. The FLD is a Monte Carlo-based method in which the magnetic field line tracing is started from a population of starting points slightly inside the last closed magnetic flux surface (LCFS). After some "free path" length, a random step perpendicular to the magnetic field, with a certain distribution of step widths, is added [24]. This corresponds to a free movement of the particles parallel to the magnetic field with thermal velocity and a diffusion perpendicular to the magnetic field. The tracing terminates when the particle hits a PFC. The PFCs considered in the present study are listed in Table 1 and previously shown in Figure 1 and in Figure 2 from the IR camera view point.

In the present work we use a starting population of 12500 points, from each of which the magnetic field is traced in both directions, resulting in a total of $n_{\text {tot }}=25000$ starting points. We further use a ratio between perpendicular and parallel transport corresponding to a parallel velocity of $2 \times 10^{5} \mathrm{~m} / \mathrm{s}$ and a perpendicular diffusion coefficient of $1 \mathrm{~m}^{2} / \mathrm{s}$.

In the end we obtain a set of hit points on the PFCs. It is assumed that the available heating power $\mathrm{P}$ is equally distributed to the $\mathrm{n}_{\text {tot }}$ hit points (i. e., the entire heating power reaches the wall as convected power $\mathrm{P}_{\text {conv }}$ ). With an appropriate choice of surface segments, as discussed in the following section, the local heat load for each segment can be calculated.

\subsection{Comparison of wall loads with design values}

Since we compute the convective heat load $\mathrm{q}_{\mathrm{i}}$ to segment no. $\mathrm{i}$ with finite surface area $\mathrm{A}_{\mathrm{i}}$ from a finite number of hits $n_{i}$,

$$
\mathrm{q}_{\mathrm{i}}=\frac{\mathrm{n}_{\mathrm{i}} \mathrm{P}_{\text {conv }}}{\mathrm{n}_{\text {tot }} \mathrm{A}_{\mathrm{i}}}
$$

some care must be taken to assess the statistical significance of the result. Since we only consider magnetic configurations and PFCs respecting the ten-fold symmetry described in section 1, we map all hit points into one half module of the device (and then need to reduce $\mathrm{q}_{\mathrm{i}}$ by the symmetry factor $\zeta=10$ ). We then proceed as described in [29]. As reported in that paper, $n_{\text {tot }}=25000$ ensures good statistics in the FLD calculations, allowing an acceptable computational time saving due to the choice of appropriate segment areas (see below). Given a design heat flux limit $\mathrm{q}_{\mathrm{d}, \mathrm{i}}$ for each segment and a number of hits $\mathrm{n}_{\mathrm{i}}$, a "probability of safe operation" can then be calculated. Low values of this probability mean that overloads likely occur. In this paper, we shall regard a segment as "overloaded" if the probability of safe operation is less than $95 \%$. In Table 1 we list the design heat flux limits for the different types of PFC. For the baffles and the heat shield, the value of $0.5 \mathrm{MW} / \mathrm{m}^{2}$ may be not conservative enough, therefore additional evaluations with $\mathrm{q}_{\mathrm{d}, \mathrm{i}}=0.25 \mathrm{MW} / \mathrm{m}^{2}$ for this type of PFC were also performed. The results obtained with the two different $\mathrm{q}_{\mathrm{d}, \mathrm{i}}$ values will be presented and compared in the following. 
Table 1. PFCs used for the FLD and corresponding original $\mathrm{q}_{\mathrm{d}, \mathrm{i}}$ values [29].

\begin{tabular}{lc}
\hline Component & $\mathrm{q}_{\mathrm{d}, \mathrm{i}}\left[\mathrm{MW} / \mathrm{m}^{2}\right]$ \\
\hline Divertor - highly loaded area & 10.0000 \\
Divertor - end tile at pumping gap & 5.0000 \\
Divertor - edge tile at pumping gap & 2.0000 \\
Divertor - TM5-6h & 0.5000 \\
Baffle & 0.5000 \\
Toroidal closure & 0.5000 \\
\hline
\end{tabular}

\subsection{Segmentation of targets and baffles}

The purpose of the new segmentation applied to the PFCs is (1) to avoid very small segment areas which would result in poor statistics and (2) to choose the segments such that the physical overload mechanism is reflected. After presenting the segmentation of the targets (as already introduced in [29]), we are introducing the segmentation of the baffle modules. We also present the visualisation of the segmentation in pixel maps, which will then be used for a representation of the heat loads and probabilities of safe operation. Indeed, a particle hitting a PFC generates, in principle, an infinite heat load. Hence, it is necessary to define a relevant size of the bins to collect particles and calculate finite heat loads. The relevant bin size for the divertor is the tile (typically $55 \times 25 \mathrm{~mm}$ ), for the baffle it is a tile of 110x110 mm and for TM5-6h, the tiles are 55x140 mm but a finer subdivision is made here since the strike line width is significantly smaller than the $140 \mathrm{~mm}$ width of the tile (see below).

Regarding the divertor, it is composed of four different parts, labelled and depicted in Figure 3 . The new segmentation for the divertor provides a two-dimensional map with well-defined neighbourhood relations (cf. bottom part of Figure 3). Each segment of the new divertor model and a scalar value belonging to that segment correspond to one pixel in the newly defined pixel map and the pixel value, respectively. Pixels that do not have a corresponding counterpart on the divertor are marked white. The new segmentation is inherited from the original mesh, following the natural tile geometry of the target modules TM1-4h, TM7-9h and TM1-3v. An artificial tile-like substructure is applied to the TM5-6h target elements (see the left half of the zoom in Figure 3), which ensures similar sized areas. Since we want to compare the heat load $\mathrm{q}_{\mathrm{i}}$ with respect to the maximal design heat load $\mathrm{q}_{\mathrm{d} ; \mathrm{i}}$, we furthermore discriminate on the basis of $\mathrm{q}_{\mathrm{d} ; \mathrm{i}}$ which is colour coded in Figure 3. This means in particular that the divertor edges facing the pumping gap between TM1-4h and TM1-3v are subdivided corresponding to lower $\mathrm{q}_{\mathrm{d}, \mathrm{i}}$ of $5.0 \mathrm{MW} / \mathrm{m}^{2}$ and $2.0 \mathrm{MW} / \mathrm{m}^{2}$ respectively (see the right half of the zoom in Figure 3), as previously reported in Table 1 . The single segments (tiles) are sorted into a 113x29 two-dimensional pixel map.

Concerning the baffle (Figure 4), its mapping has been realized following the same rationale and using a 50x12 two-dimensional pixel map (Figure 5), defining single baffle tiles as segments. In order to facilitate the identification of individual tiles between the CAD view (Figure 4) and the pixel map (Figure 5), different colours distinguish the individual baffle modules. Also in this case, white pixels do not correspond to any tile. 


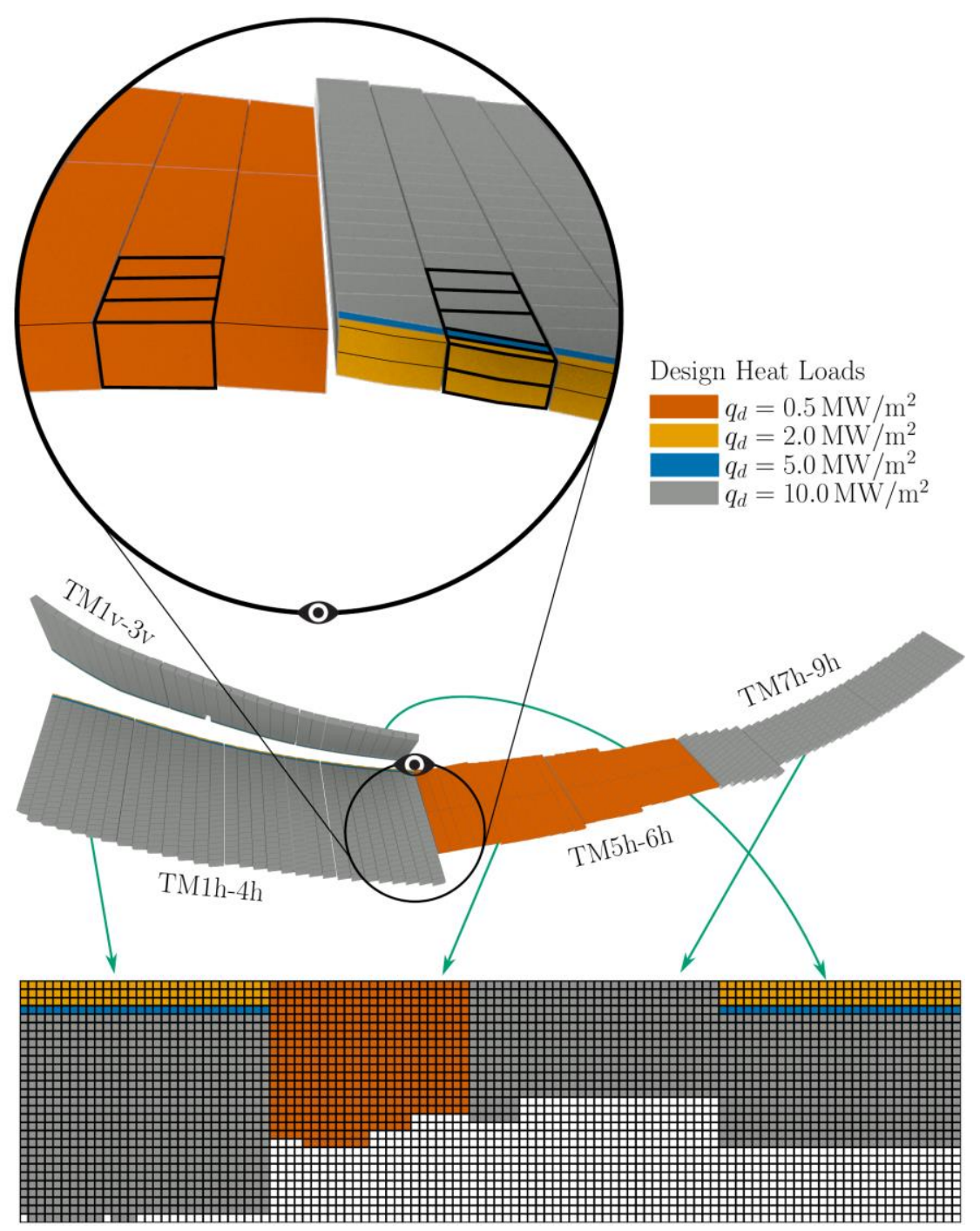

Figure 3. Geometry and two-dimensional pixel map for the divertor [29].
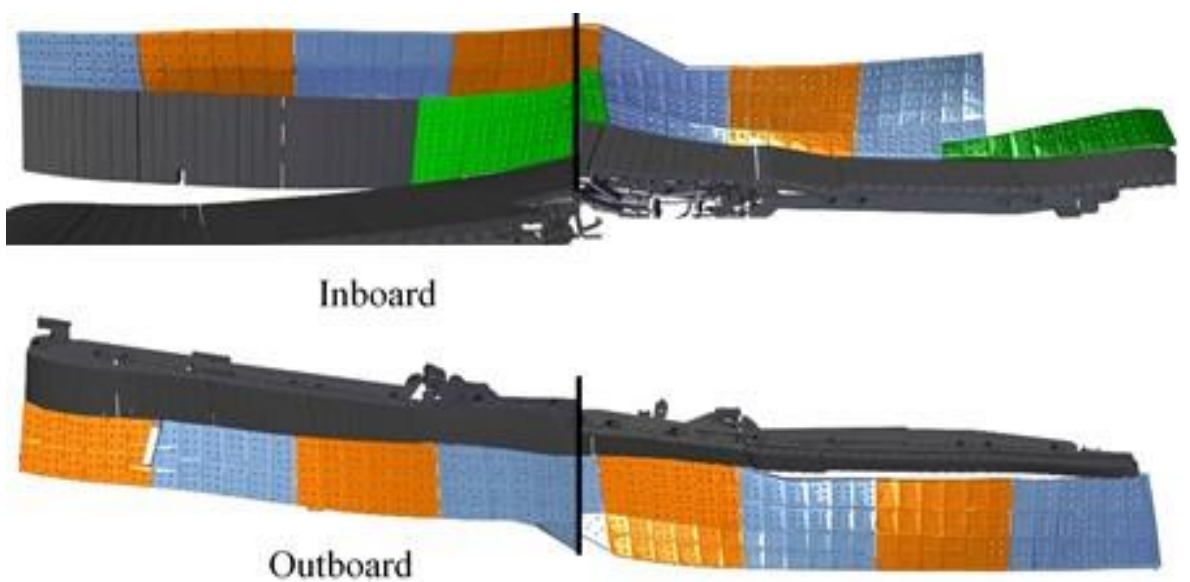

Figure 4. Baffle geometric domain, derived from several CAD views. 


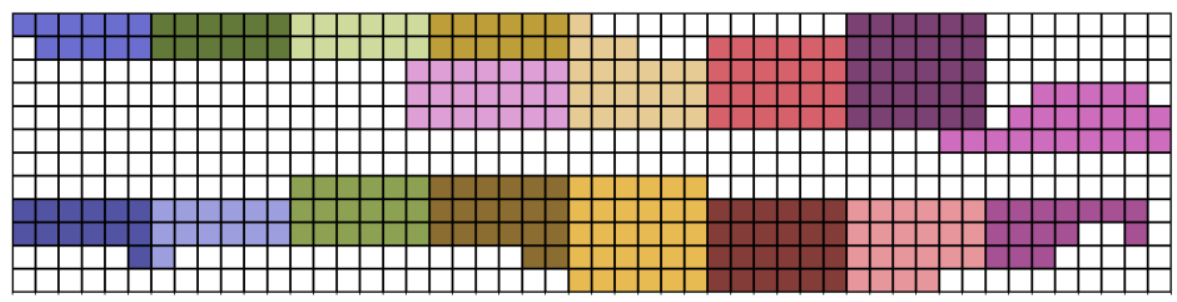

Figure 5. Two-dimensional pixel map for the baffle modelling.

\subsection{Criteria for the choice of locations for temperature monitoring}

There are some 320 baffle tiles per divertor unit, and we calculated heat loads for about 100 different magnetic configurations. For each magnetic configuration, we recorded those tiles with statistically significant loads above their design limit for a total heating power of $8.0 \mathrm{MW}$, if any ( $8 \mathrm{MW}$ will be the available continuous-wave heating power at the beginning of the next operation phase - in the framework of the FLD model, the convective power load to each wall component scales linearly with the total heating power). They are typically localised in one or few clusters in each magnetic configuration. For each such cluster we marked the 1-3 tiles with the largest overloads. We note that in many configurations, the same tiles were those with the largest overload. This reflects the fact that the shape of the LCFS does not vary too much between different magnetic configurations, such that there are always certain tiles in each part of the baffle which are closest to the LCFS and receive the highest heat load.

For our choice it is not important that in some cases many tiles are overloaded and that some of them receive almost a factor of 10 more power than their design limit. Of course, such a configuration will never be run. Rather, such configurations will be modified, e. g. by shifting the plasma column radially or by changing the radial location or size of the boundary islands. Nevertheless, we expect that one of the selected tiles will still receive the highest heat load, such that they are the appropriate choice for temperature monitoring for any magnetic configuration. Due to symmetry breaking magnetic field errors [32][33], slight misalignments of the PFCs, and drift effects, asymmetries between the heat loads to the 10 different divertor units are observed [34] [35], which may differ between configurations and with the sign of the magnetic field. It is therefore necessary to monitor the temperature of the heat sinks of the selected tiles in every of the 10 divertor units.

\section{Results of overload analysis}

In order to investigate the overloads arising onto baffle and divertor tiles in finite- $\beta$ configurations, FLD calculations for the magnetic configurations listed in Table 2 are performed. In particular, 7 different vacuum field configurations are chosen (called standard, low shear (orig./mod.), outward shifted, low iota, high mirror and high iota) and, for each of them, three different values of $\beta$ are chosen for VMEC calculations. Configurations with finite plasma current are not covered in this work.

Table 2. Considered finite- $\beta$ magnetic configurations. The notation refers to the $\mathrm{W} 7-\mathrm{X}$ reference 
configurations as defined in [25] - the "Low shear (mod.)" configurations has slightly modified current ratios in the field coils.

\begin{tabular}{|c|c|c|}
\hline Id & Configuration & $\beta$ \\
\hline 1 & Standard & $1.32 \%$ \\
\hline 2 & Standard & $2.00 \%$ \\
\hline 3 & Standard & $3.39 \%$ \\
\hline 4 & Low shear (orig.) & $1.00 \%$ \\
\hline 5 & Low shear (orig.) & $2.00 \%$ \\
\hline 6 & Low shear (orig.) & $3.10 \%$ \\
\hline 7 & Low shear (mod.) & $1.20 \%$ \\
\hline 8 & Low shear (mod.) & $2.50 \%$ \\
\hline 9 & Low shear (mod.) & $3.80 \%$ \\
\hline 10 & Outward shifted & $1.00 \%$ \\
\hline 11 & Outward shifted & $2.00 \%$ \\
\hline 12 & Outward shifted & $3.20 \%$ \\
\hline 13 & Low iota & $1.00 \%$ \\
\hline 14 & Low iota & $2.00 \%$ \\
\hline 15 & Low iota & $3.10 \%$ \\
\hline 16 & High mirror & $0.83 \%$ \\
\hline 17 & High mirror & $1.68 \%$ \\
\hline 18 & High mirror & $3.44 \%$ \\
\hline 19 & High iota & $1.02 \%$ \\
\hline 20 & High iota & $2.08 \%$ \\
\hline 21 & High iota & $3.16 \%$ \\
\hline 22 & High iota - new BCs & $3.17 \%$ \\
\hline
\end{tabular}

For each of the considered magnetic configurations, FLD calculations using 25000 traces are performed.

A summary of the hit point locations is reported in Table 3. There, "Other components" comprise toroidal closure, heat shield and wall panels. For each magnetic configuration, the two cases of $\mathrm{P}_{\text {conv }}=$ 5.0 MW and $\mathrm{P}_{\text {conv }}=8.0 \mathrm{MW}$ are assessed.

Table 3. Number of hit points. 


\begin{tabular}{|c|c|c|c|}
\hline Id & Baffle & Targets & Other components \\
\hline 1 & 665 & 23049 & 1286 \\
\hline 2 & 1087 & 22627 & 1286 \\
\hline 3 & 4327 & 18934 & 1739 \\
\hline 4 & 3981 & 19636 & 1383 \\
\hline 5 & 12743 & 9837 & 2420 \\
\hline 6 & 20722 & 1976 & 2302 \\
\hline 7 & 18063 & 5445 & 1492 \\
\hline 8 & 22315 & 686 & 1999 \\
\hline 9 & 23486 & 21 & 1493 \\
\hline 10 & 3343 & 20477 & 1180 \\
\hline 11 & 12463 & 11267 & 1270 \\
\hline 12 & 19497 & 3603 & 1900 \\
\hline 13 & 416 & 23266 & 1318 \\
\hline 14 & 538 & 22805 & 1657 \\
\hline 15 & 6622 & 16891 & 1487 \\
\hline 16 & 1240 & 22525 & 1235 \\
\hline 17 & 1362 & 22378 & 1260 \\
\hline 18 & 1169 & 22434 & 1397 \\
\hline 19 & 55 & 22194 & 2751 \\
\hline 20 & 61 & 20570 & 4369 \\
\hline 21 & 192 & 18700 & 6108 \\
\hline 22 & 41 & 20991 & 3968 \\
\hline
\end{tabular}

\subsection{Targets}

The results obtained for the target overloads evaluation in the considered 22 magnetic configurations are summarized in Table 4.

The word "Safe" indicates that no overloads are predicted in the considered scenario, whereas the word "Overloaded" means that at least one overloaded tile (as defined in section 2.2) is detected in that loading conditions.

Table 4. Results summary - target plates. 


\begin{tabular}{|c|c|c|}
\hline Id & $\mathrm{P}_{\text {conv }}=5.0 \mathrm{MW}$ & $\mathrm{P}_{\text {conv }}=8.0 \mathrm{MW}$ \\
\hline 1 & Safe & Safe \\
\hline 2 & Safe & Safe \\
\hline 3 & Safe & Safe \\
\hline 4 & Safe & Safe \\
\hline 5 & Safe & Safe \\
\hline 6 & Safe & Safe \\
\hline 7 & Safe & Safe \\
\hline 8 & Safe & Safe \\
\hline 9 & Safe & Safe \\
\hline 10 & Safe & Safe \\
\hline 11 & Safe & Safe \\
\hline 12 & Safe & Safe \\
\hline 13 & Safe & Overloaded \\
\hline 14 & Safe & Safe \\
\hline 15 & Safe & Safe \\
\hline 16 & Safe & Safe \\
\hline 17 & Safe & Safe \\
\hline 18 & Safe & Safe \\
\hline 19 & Safe & Safe \\
\hline 20 & Safe & Overloaded \\
\hline 21 & Safe & Overloaded \\
\hline 22 & Safe & Safe \\
\hline
\end{tabular}

As reported in Table 4, the target plates are not overloaded in any of the magnetic configurations for a total convected power of 5.0 MW. On the other hand, when a total convected power of 8.0 MW is assumed, configuration 13 (belonging to "Low Iota" group), 20 and 21 (belonging to "High Iota" group) show overloads on the divertor targets.

The results for these three configurations are shown in Appendix A.1, where it can be seen that the overloads are marginal and will therefore be avoided for slightly changed discharge conditions (e. g., if a fraction of the heating power is radiated rather than deposited to the target plates).

\subsection{Baffles}

The results for the baffles are reported in Table 5 for the two values of convected power (5.0 and 8.0 
MW) taken into account and, for each of them, for the two heat flux limit considered $\left(\mathrm{q}_{\mathrm{d}, \mathrm{i}}=0.5 \mathrm{MW} / \mathrm{m}^{2}\right.$ and $\mathrm{q}_{\mathrm{d}, \mathrm{i}}=0.25 \mathrm{MW} / \mathrm{m}^{2}$ ). Obviously, the case with $\mathrm{P}_{\text {conv }}=8.0 \mathrm{MW}$ and $\mathrm{q}_{\mathrm{d}, \mathrm{i}}=0.25 \mathrm{MW} / \mathrm{m}^{2}$ is the most critical one. The complete set of results for the overloaded configurations in the latter case are shown in Appendix A.2.

Table 5. Results summary - baffle.

\begin{tabular}{|c|c|c|c|c|}
\hline \multirow[t]{2}{*}{ Id } & \multicolumn{2}{|c|}{$\mathrm{q}_{\mathrm{d}, \mathrm{i}}=0.50 \mathrm{MW} / \mathrm{m}^{2}$} & \multicolumn{2}{|c|}{$\mathrm{q}_{\mathrm{d}, \mathrm{i}}=0.25 \mathrm{MW} / \mathrm{m}^{2}$} \\
\hline & $\mathrm{P}_{\text {conv }}=5 \mathrm{MW}$ & $\mathrm{P}_{\text {conv }}=8 \mathrm{MW}$ & $\mathrm{P}_{\text {conv }}=5 \mathrm{MW}$ & $\mathrm{P}_{\text {conv }}=8 \mathrm{MW}$ \\
\hline 1 & Safe & Safe & Safe & Safe \\
\hline 2 & Safe & Safe & Safe & Overloaded \\
\hline 3 & Overloaded & Overloaded & Overloaded & Overloaded \\
\hline 4 & Overloaded & Overloaded & Overloaded & Overloaded \\
\hline 5 & Overloaded & Overloaded & Overloaded & Overloaded \\
\hline 6 & Overloaded & Overloaded & Overloaded & Overloaded \\
\hline 7 & Overloaded & Overloaded & Overloaded & Overloaded \\
\hline 8 & Overloaded & Overloaded & Overloaded & Overloaded \\
\hline 9 & Overloaded & Overloaded & Overloaded & Overloaded \\
\hline 10 & Safe & Overloaded & Overloaded & Overloaded \\
\hline 11 & Overloaded & Overloaded & Overloaded & Overloaded \\
\hline 12 & Overloaded & Overloaded & Overloaded & Overloaded \\
\hline 13 & Safe & Safe & Safe & Overloaded \\
\hline 14 & Safe & Safe & Safe & Safe \\
\hline 15 & Overloaded & Overloaded & Overloaded & Overloaded \\
\hline 16 & Safe & Safe & Overloaded & Overloaded \\
\hline 17 & Safe & Overloaded & Overloaded & Overloaded \\
\hline 18 & Safe & Safe & Overloaded & Overloaded \\
\hline 19 & Safe & Safe & Safe & Safe \\
\hline 20 & Safe & Safe & Safe & Safe \\
\hline 21 & Safe & Safe & Safe & Safe \\
\hline 22 & Safe & Safe & Safe & Safe \\
\hline
\end{tabular}




\subsection{Further wall protection tiles}

Inspection of Table 3 reveals that for configurations 19-22 (high-iota), more than $10 \%$ of the FLD traces hit "other components" than targets or baffles. We found that most of these hits are on a few wall protection tiles on the torus outboard side close to the module separation plane, and that the highest loaded of these tiles may be severely overloaded (Figure 6). In addition, this area is very poorly or even not at all surveyed by the infrared cameras. We therefore added 2-4 locations per half module in this area to the list of locations for thermocouples.

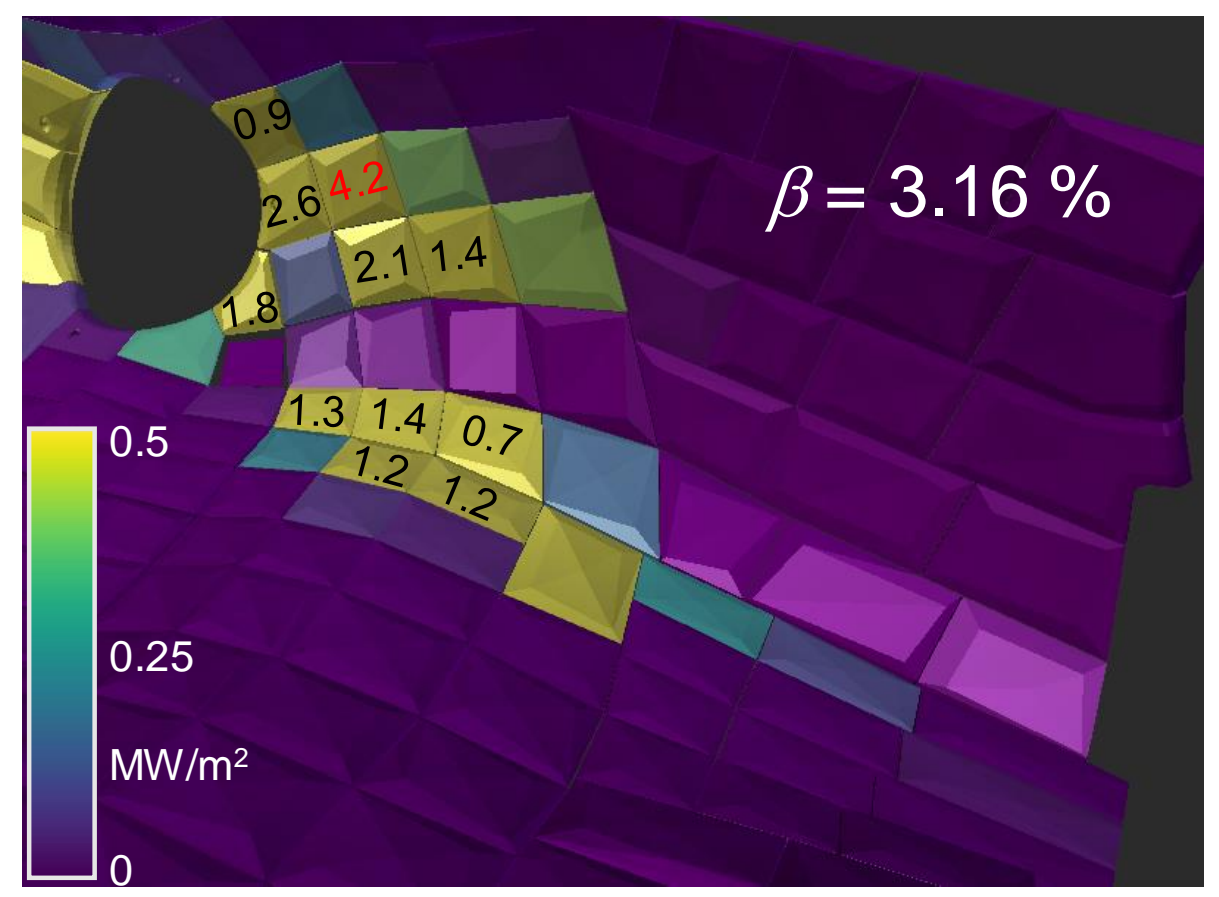

Figure 6. Example of heat loads in one of the triangular planes (between machine modules 3 and 4 and between 4 and 5) for the high-iota configuration with $\beta=3.16 \%$. The numbers on the highest loaded tiles are the heat loads in $\mathrm{MW} / \mathrm{m}^{2}$.

\subsection{Radiative loads}

In addition to the convective loads, thermal loads onto the baffle tiles due to plasma radiation have been assessed. To this end, the plasma radiation is either assumed to be emitted by line sources originating either from the $\mathrm{X}$ points of the edge islands or from their $\mathrm{O}$ points (see section 1), since these two origins are localised closest to the baffles and therefore are expected to cause the highest thermal loads. For both the "X" and the "O" source distributions, a total radiative heat power of 8.0 MW was assumed. Test particles representing radiation photons were started on either the " $\mathrm{X}$ " or the "O" lines with random direction, and their hit points at wall components were registered. This set of hit points was further processed adopting the same methodology as before for the hit points from FLD.

Assuming conservatively $\mathrm{q}_{\mathrm{d}, \mathrm{i}}=0.25 \mathrm{MW} / \mathrm{m}^{2}$, no overloading has been found. As to "O" distribution, a maximum heat flux of $0.147 \mathrm{MW} / \mathrm{m}^{2}$ on the baffle has been calculated. Moreover, regarding the " $\mathrm{X}$ " distribution, a maximum heat flux equal to $0.072 \mathrm{MW} / \mathrm{m}^{2}$ has been observed for the baffle tiles. 
For a given heating power, the fractions reaching the wall as convective load and as radiation must sum up to the total heating power. Any combination of convective and radiative load will therefore always be lower than the worst case load for any given wall component. As no concerns arise for the baffle from radiative heat transfer, only the overload cases of convective load need to be considered.

\section{Choice of thermocouple locations}

As discussed in section 2.4, the wall protection tiles with overloads in some of the magnetic configurations considered are clustered in a limited number of locations, and the same very few tiles within each cluster are predicted to receive the highest load even in different magnetic configurations. Those are the obvious choice for the thermocouples placement. In addition, care is taken on the one hand side to provide temperature monitoring in those critical locations that are not visible in the divertor thermography system, but on the other side also to place thermocouples in some locations that are visible by thermography in order to compare the information gathered by the two diagnostic methods.

Based on the results presented in section 3 and in the Appendix and on the analysis of further vacuum configurations [29], 25-29 locations in baffle heat sinks per divertor unit and 2-4 locations in the heat sinks of wall protection tiles per half module were chosen, as shown in Figure 7 and Figure 8. The thermocouples will be integrated before the next operational phase of W7-X into the heat sinks in the chosen locations (or, in few instances, in slightly shifted locations, due to space restrictions).

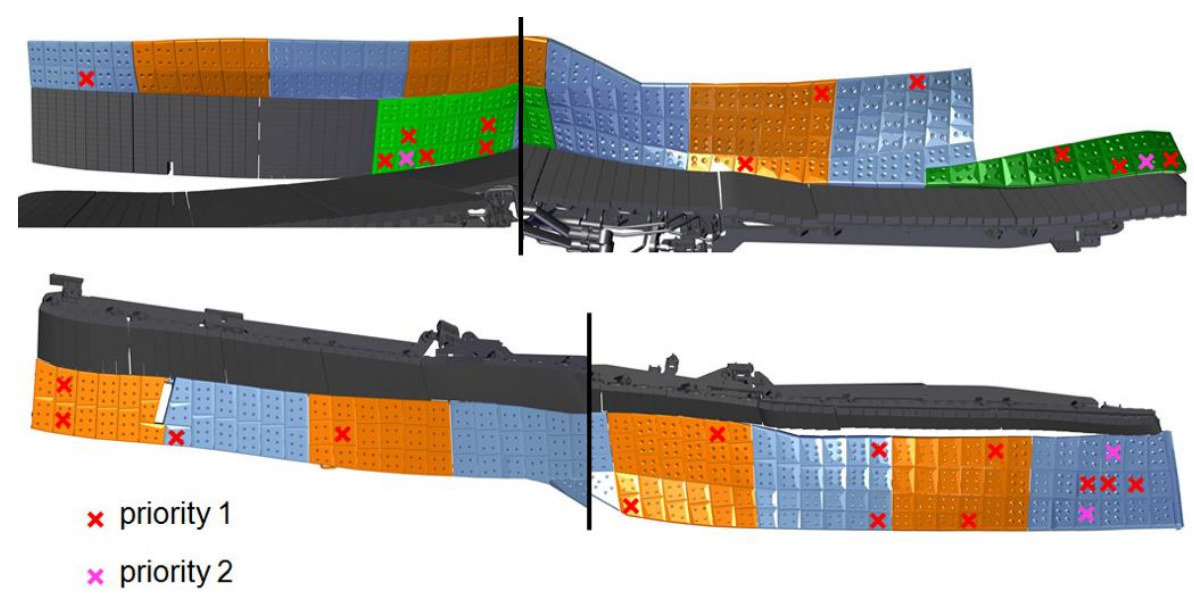

Figure 7. Baffle tiles chosen for addition of thermocouples into their heat sinks (25 priority-1 and 4 priority-2 per half module). 


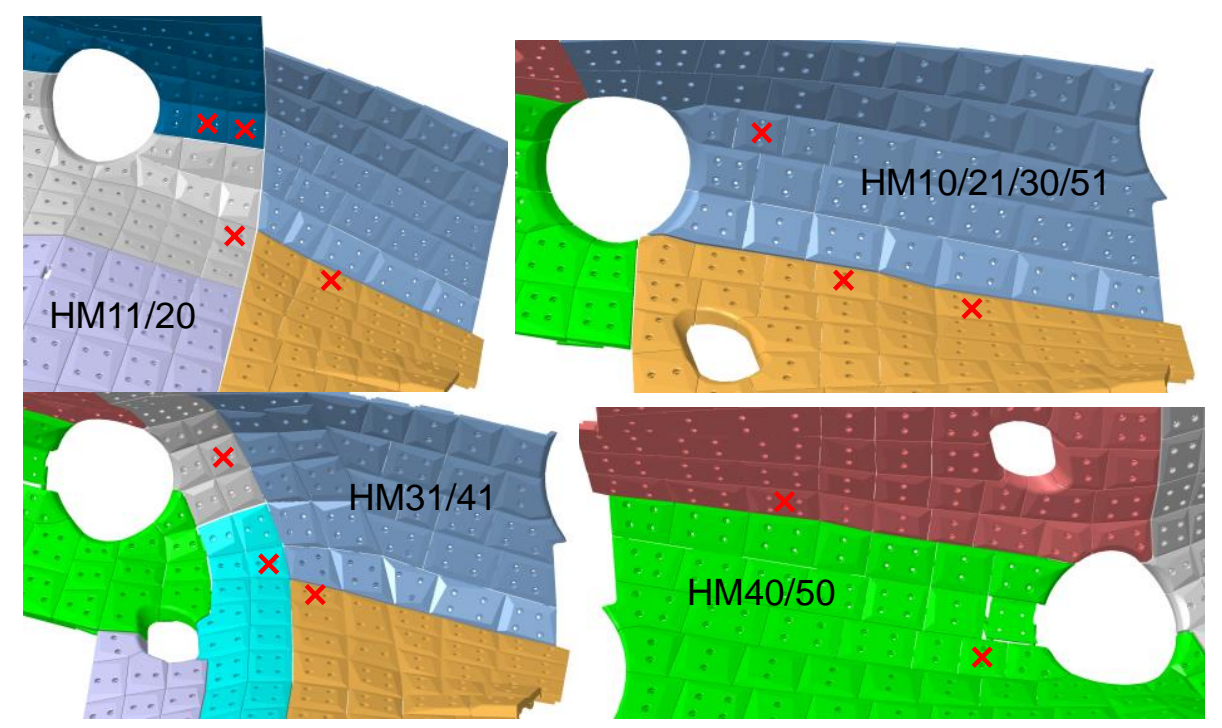

Figure 8. Tiles of the heat shield in the module separation planes chosen for addition of thermocouples into their heat sinks. Here, the design varies between half modules such that an individual assessment of the 4 different designs was necessary.

\section{Conclusion}

In the framework of W7-X R\&D activities, an assessment of the overloads arising onto divertor, baffle and heat shield in finite- $\beta$ magnetic configurations is reported in this paper. To this purpose a calculation procedure, aimed at finding out those tiles where the predicted convective heat flux exceeds the limit, is applied. The study is carried out assuming, for the baffle and heat shield, limits of 0.50 $\mathrm{MW} / \mathrm{m}^{2}$ and $0.25 \mathrm{MW} / \mathrm{m}^{2}$. A maximum convected heat power of $8.0 \mathrm{MW}$ is considered.

Results show that baffle and heat shield tiles in some regions are overloaded for several of the magnetic configurations investigated, partly even for reduced total convected power or for the higher limit of $0.50 \mathrm{MW} / \mathrm{m}^{2}$. Based on this analysis, for each of the 10 divertor units/half modules, 27-33 locations are therefore selected for temperature monitoring with thermocouples to be placed right into the $\mathrm{CuCrZr}$ heat sinks, which is the relevant location for the specified heat load limit. If, during plasma operation, the temperature limit in one of those locations should be approached, the considerable flexibility of the W7-X magnet system can be used to modify the vacuum magnetic field in successive plasma discharges to reduce the thermal load in the critical locations.

Lastly, it is found that plasma radiative heat flux should not represent a concern since, even if the highest considered power is assumed to be totally radiated, heat flux on the baffle does not exceed the specified limit.

\section{Appendix}

\section{A.1 Target overload cases}

As discussed in section 3.1, overloads on the divertor targets are predicted for some magnetic configurations (13, 20 and 21, cf. Table 2 and Table 4) when a $\mathrm{P}_{\text {conv }}=8.0 \mathrm{MW}$ is assumed. 
In configuration 13 (Figure 9 and Figure 10), a maximum heat flux of $4.30 \mathrm{MW} / \mathrm{m}^{2}$ is calculated onto tile 395 (TM1-4h region, within the high loaded area) but, since the limit in this region is 10.0 $\mathrm{MW} / \mathrm{m}^{2}$, it can be considered safe. However, overloads are predicted on TM5-6h region where the heat flux limit is $0.50 \mathrm{MW} / \mathrm{m}^{2}$. In particular, the minimum probability of safe operation is found for tile 880 , where a heat flux equal to $0.60 \mathrm{MW} / \mathrm{m}^{2}$ has been calculated.

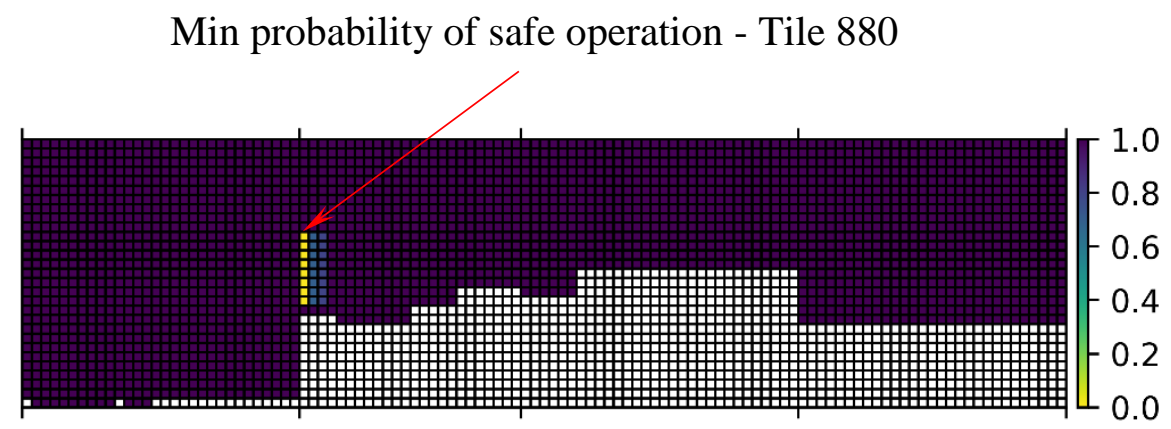

Figure 9. Configuration $13-\mathrm{P}_{\mathrm{conv}}=8.0 \mathrm{MW}-$ probability of safe operation.
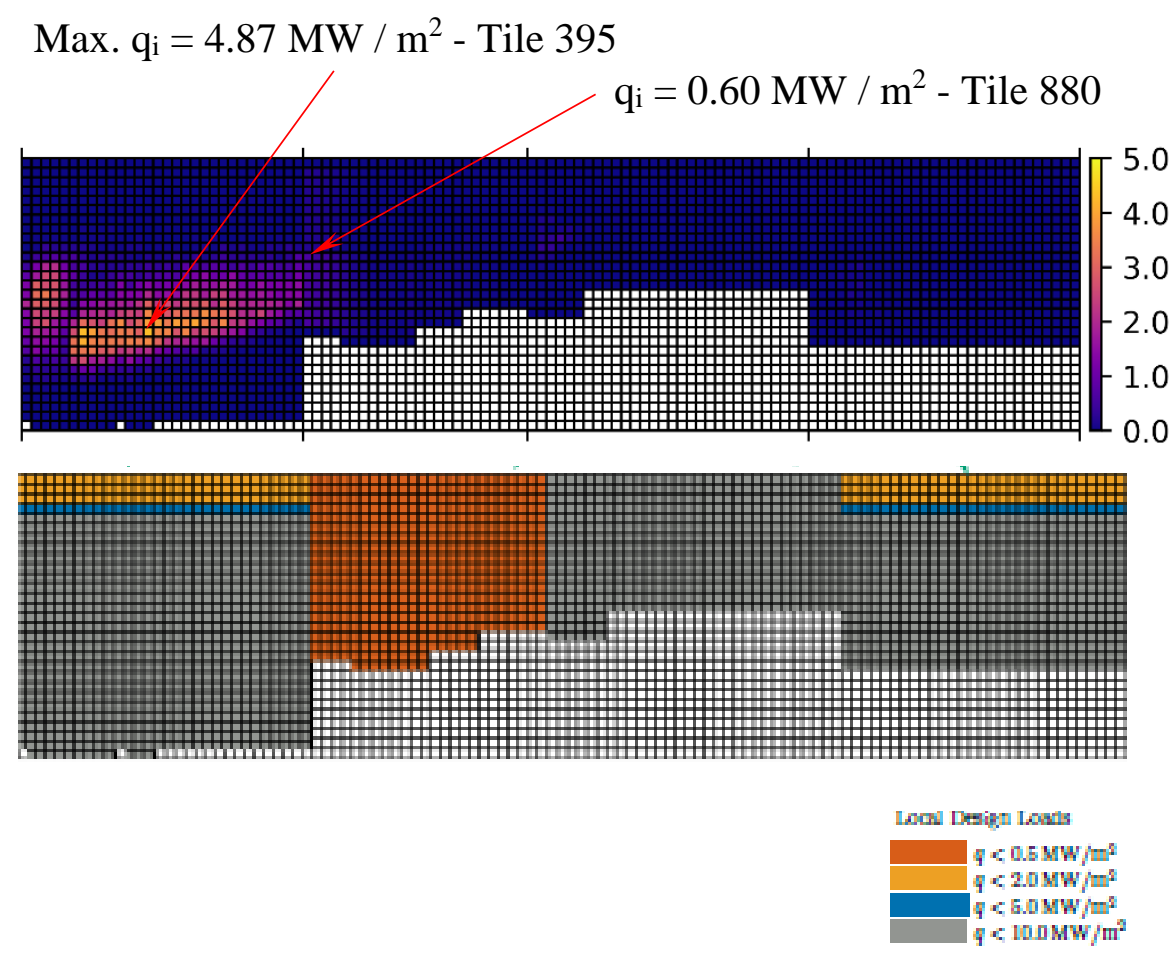

Figure 10. Configuration $13-\mathrm{P}_{\mathrm{conv}}=8.0 \mathrm{MW}-\mathrm{q}_{\mathrm{i}}\left[\mathrm{MW} / \mathrm{m}^{2}\right]$ and $\mathrm{q}_{\mathrm{d}, \mathrm{i}}$ spatial distribution.

Regarding Configuration 20 (Figure 11 and Figure 12) and Configuration 21 (Figure 13 and Figure 14), a maximum heat flux practically equal to the limit of $10.0 \mathrm{MW} / \mathrm{m}^{2}$ is predicted for tiles 2357 and 2416. The statistical analysis classifies this as an unsafe operating condition and, therefore, as a case of target overload. 
Min probability of safe operation - Tile 2357

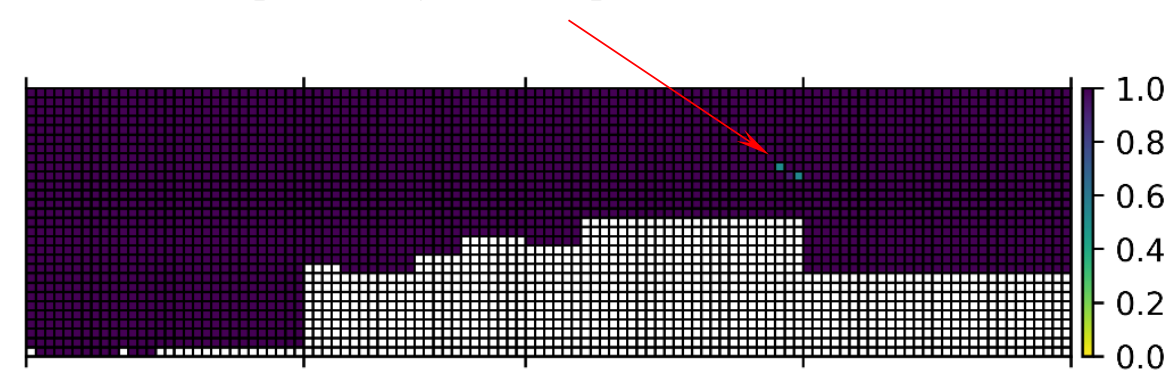

Figure 11. Configuration $20-\mathrm{P}_{\text {conv }}=8.0 \mathrm{MW}$ - probability of safe operation.
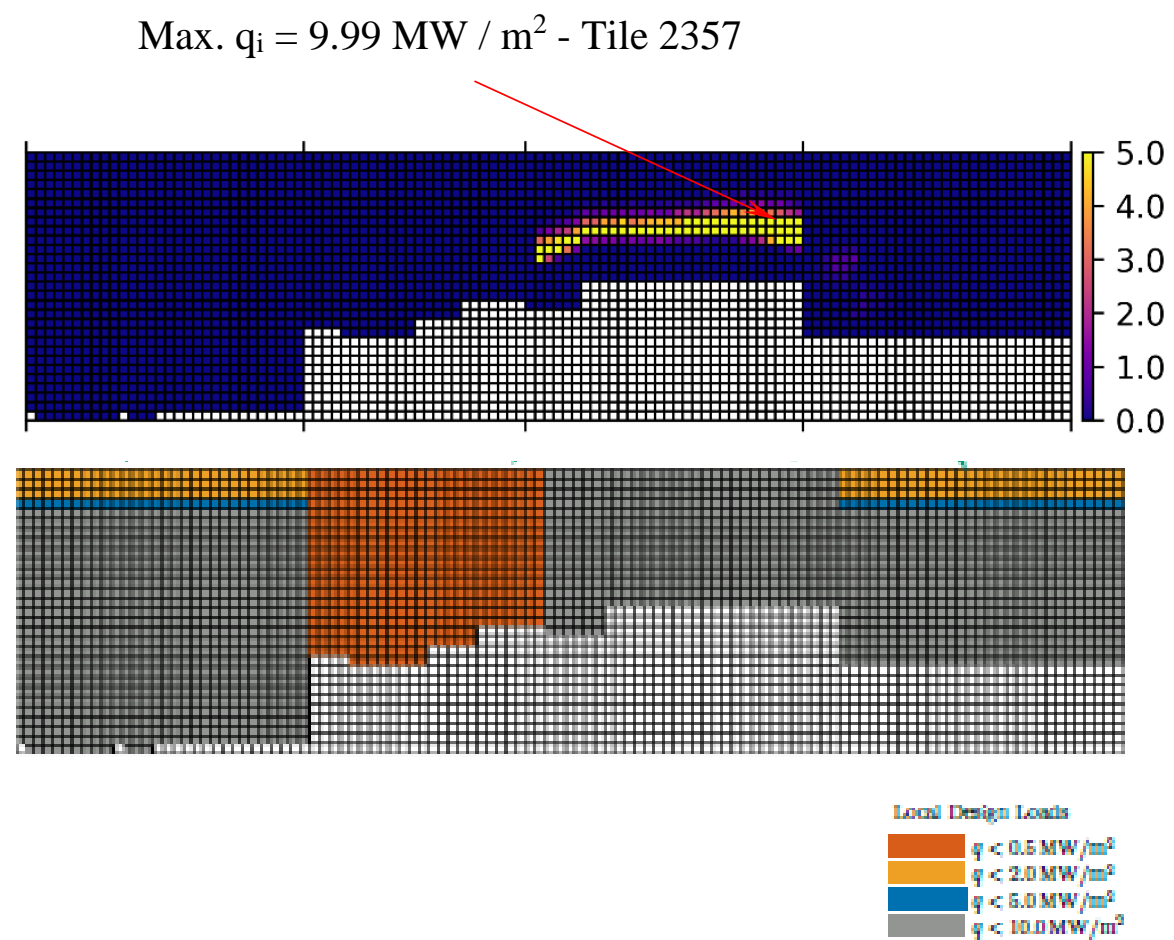

Figure 12. Configuration $20-\mathrm{P}_{\mathrm{conv}}=8.0 \mathrm{MW}-\mathrm{q}_{\mathrm{i}}\left[\mathrm{MW} / \mathrm{m}^{2}\right]$ and $\mathrm{q}_{\mathrm{d}, \mathrm{i}}$ spatial distribution.

Min probability of safe operation - Tile 2416

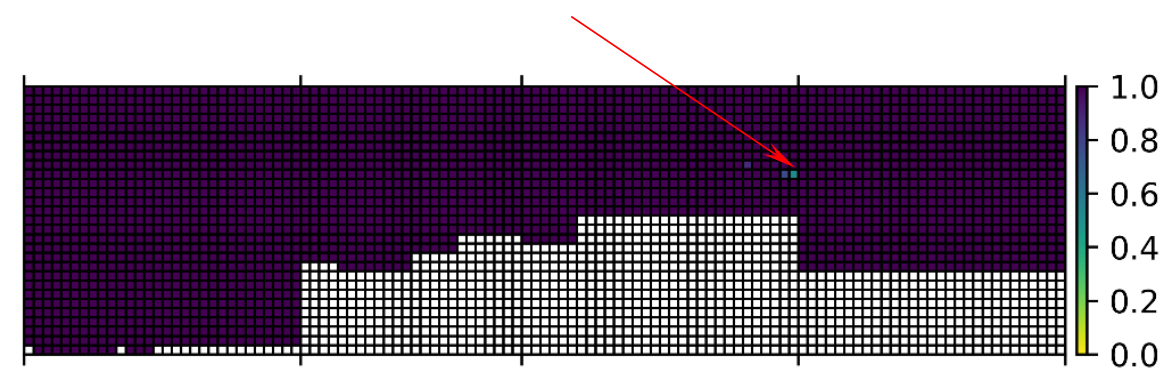

Figure 13. Configuration $21-\mathrm{P}_{\mathrm{conv}}=8.0 \mathrm{MW}-$ probability of safe operation. 

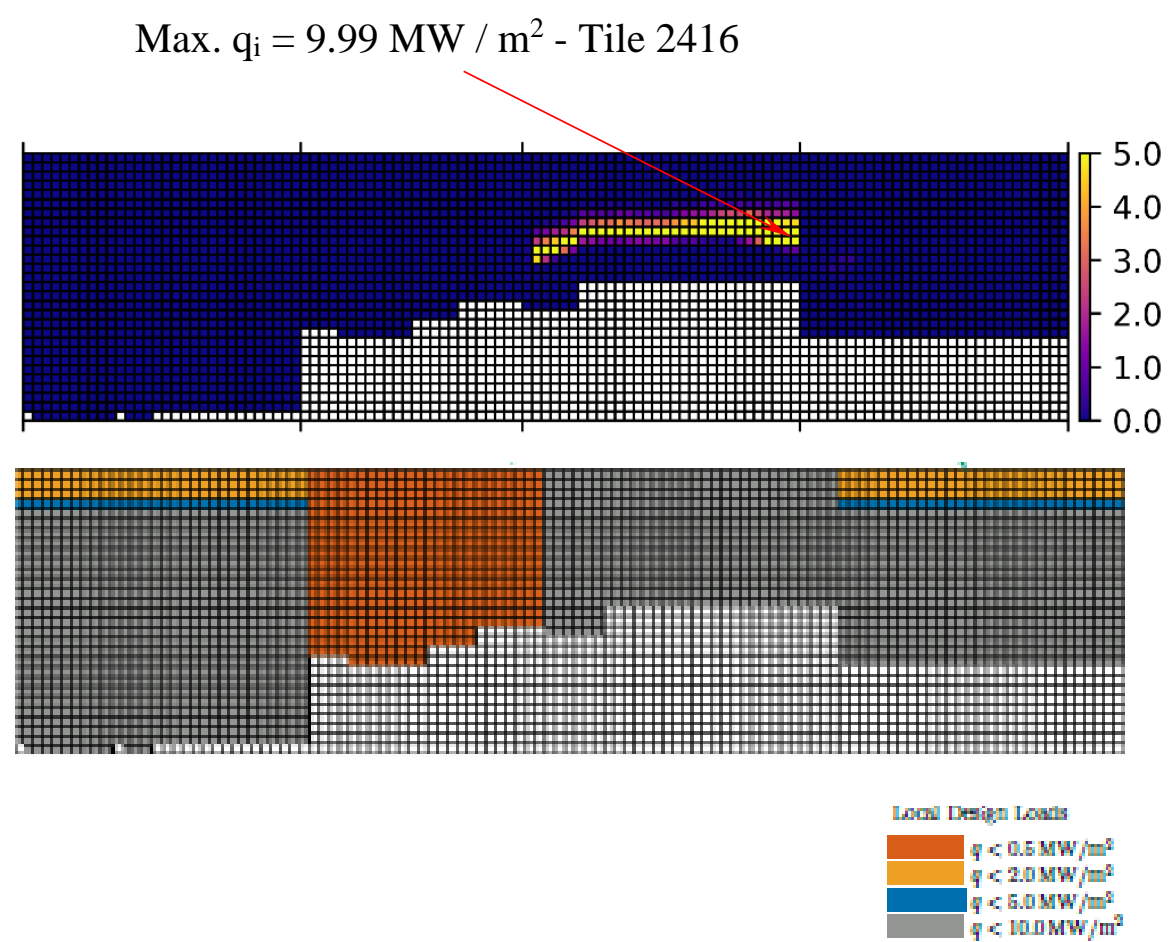

Figure 14. Configuration $21-\mathrm{P}_{\mathrm{conv}}=8.0 \mathrm{MW}-\mathrm{q}_{\mathrm{i}}\left[\mathrm{MW} / \mathrm{m}^{2}\right]$ and $\mathrm{q}_{\mathrm{d}, \mathrm{i}}$ spatial distribution.

\section{A.2 Baffle overload cases}

As discussed in section 3.2, the case with $\mathrm{P}_{\text {conv }}=8.0 \mathrm{MW}$ and $\mathrm{q}_{\mathrm{d}, \mathrm{i}}=0.25 \mathrm{MW} / \mathrm{m}^{2}$ is the most critical one. Hence, the complete set of results for the overloaded configuration in this case is here reported.

Considering "Standard iota" magnetic configurations (Id 1-3, as reported in Table 2), results have shown that the most overloaded configuration is the number $3(\beta=3.39 \%)$. The corresponding results are shown in Figure 15 (probability of safe operation) and Figure 16 (heat flux). In Figure 17, the overloaded tiles are highlighted in the CAD view of the inboard and outboard baffle modules. In this latter picture, red dots indicate tiles already overloaded with $\mathrm{q}_{\mathrm{d}, \mathrm{i}}=0.50 \mathrm{MW} / \mathrm{m}^{2}$ whereas green dots represent additional overloads arising when the heat flux limit is reduced to $\mathrm{q}_{\mathrm{d}, \mathrm{i}}=0.25 \mathrm{MW} / \mathrm{m}^{2}$.

Min probability of safe operation - Tile 228

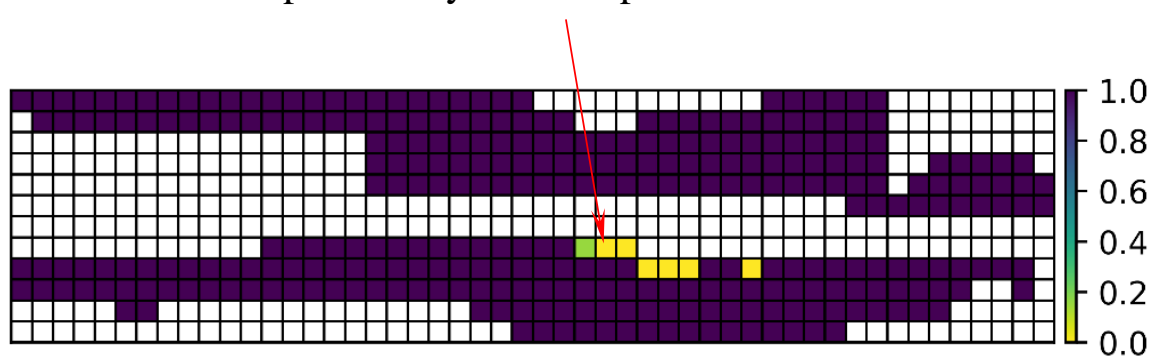

Figure 15. Configuration $3-\mathrm{P}_{\mathrm{conv}}=8.0 \mathrm{MW}$ - probability of safe operation. 


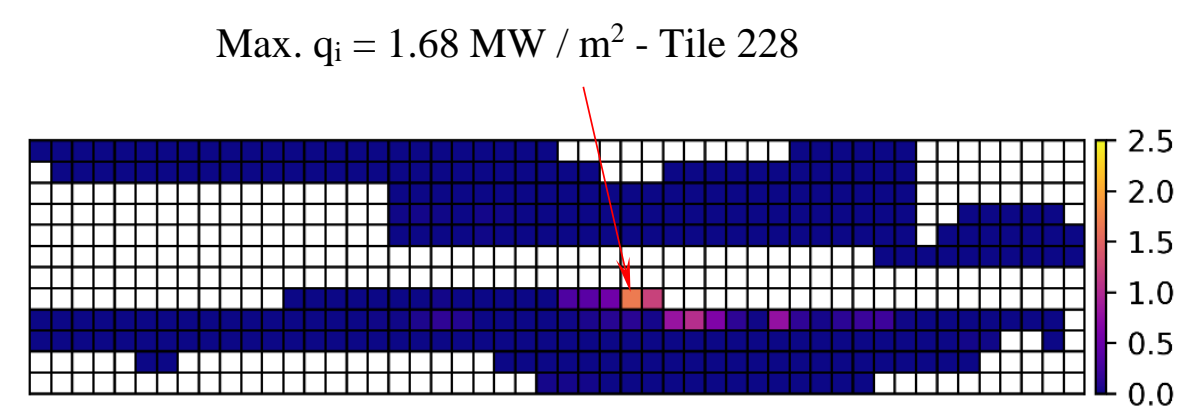

Figure 16. Configuration $3-\mathrm{P}_{\mathrm{conv}}=8.0 \mathrm{MW}-\mathrm{q}_{\mathrm{i}}\left[\mathrm{MW} / \mathrm{m}^{2}\right]$.

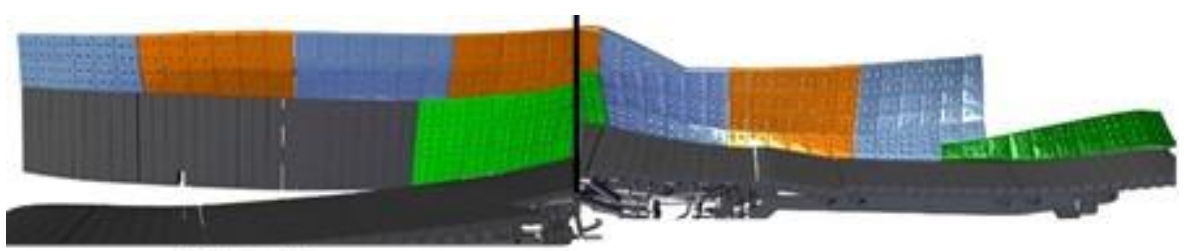

Inboard

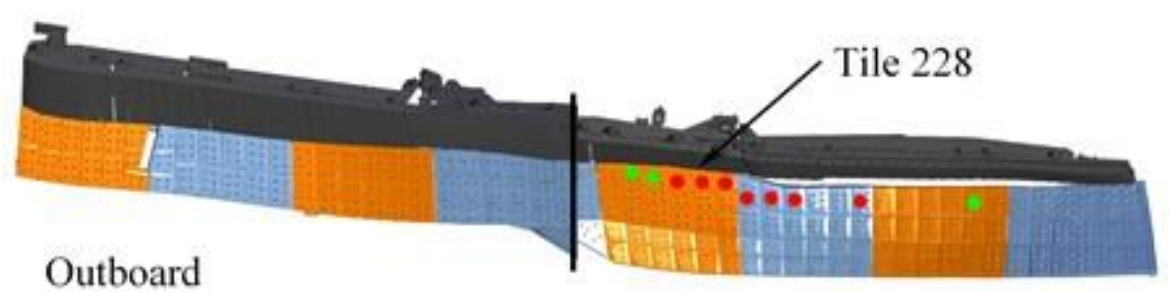

Figure 17. Configuration $3-\mathrm{P}_{\text {conv }}=8.0 \mathrm{MW}$ - Overloads.

As to "Low shear (orig.)" magnetic configurations (Id 4-6, as reported in Table 2), results have shown that the overloaded area moves towards the centre of the outboard baffle as $\beta$ increases (Figure 18). Moreover, the most overloaded configuration is that characterised by the highest $\beta$, namely Configuration 6 with $\beta=3.10 \%$. For this latter configuration, the heat flux distribution predicted for the baffle is shown in Figure 19. Finally, the overloaded tiles are highlighted in Figure 20 on a CAD representation of the baffle modules. In this latter picture, red dots indicate tiles already overloaded with $\mathrm{q}_{\mathrm{d}, \mathrm{i}}=0.50 \mathrm{MW} / \mathrm{m}^{2}$ whereas green dots represent additional overloads arising when the heat flux limit is reduced to $\mathrm{q}_{\mathrm{d}, \mathrm{i}}=0.25 \mathrm{MW} / \mathrm{m}^{2}$. 


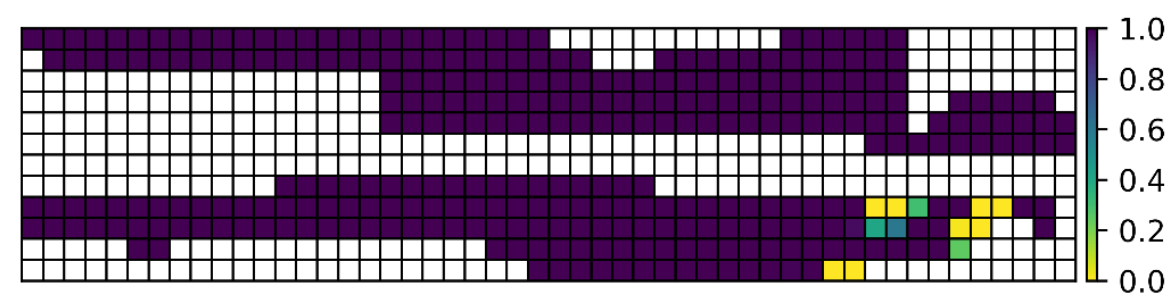

Configuration 4

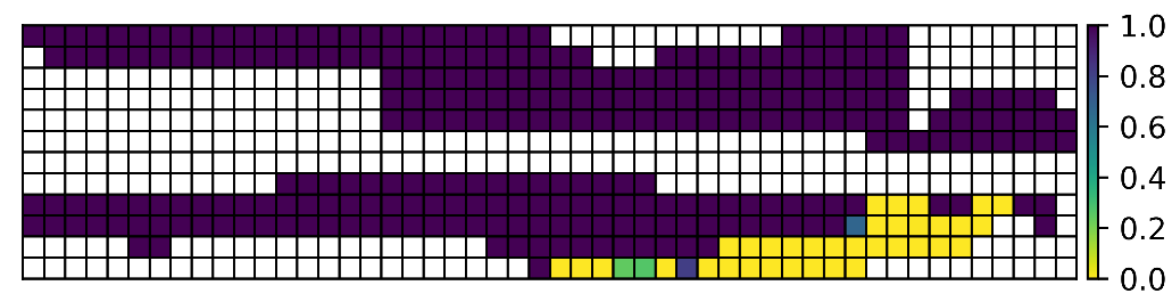

Configuration 5

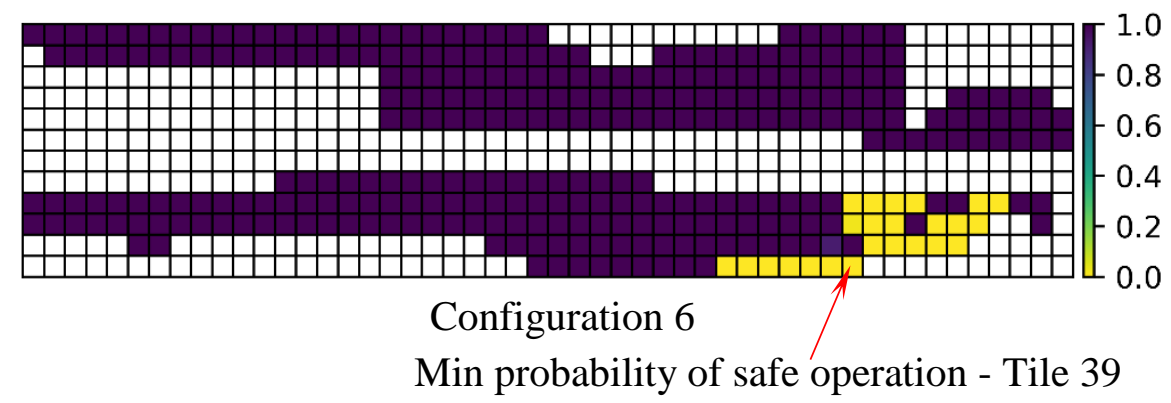

Figure 18. Low shear (orig.) configurations $-\mathrm{P}_{\text {conv }}=8.0 \mathrm{MW}-$ probability of safe operation.

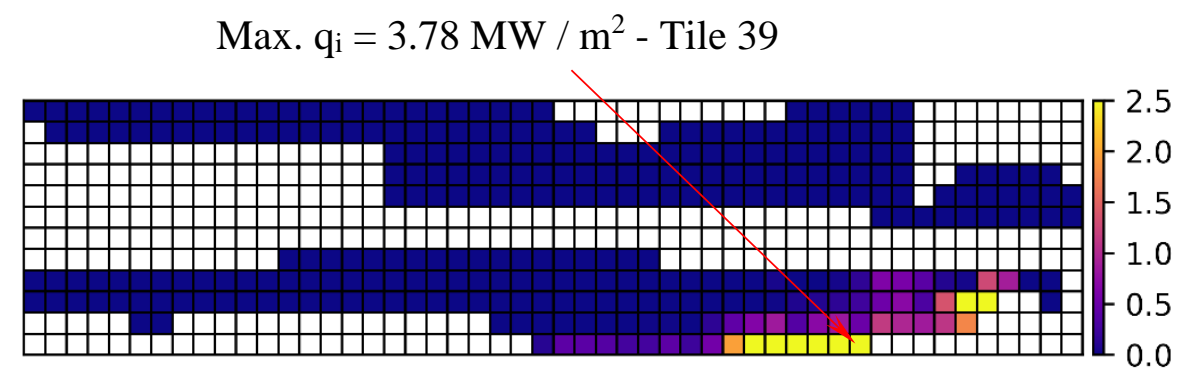

Figure 19. Configuration $6-\mathrm{P}_{\mathrm{conv}}=8.0 \mathrm{MW}-\mathrm{q}_{\mathrm{i}}\left[\mathrm{MW} / \mathrm{m}^{2}\right]$.

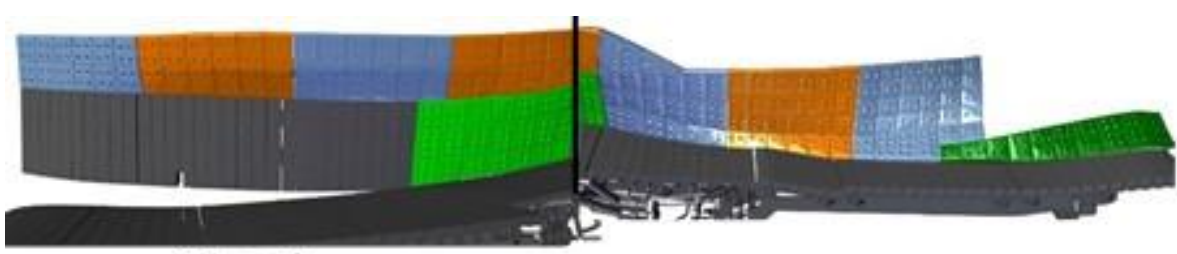

Inboard

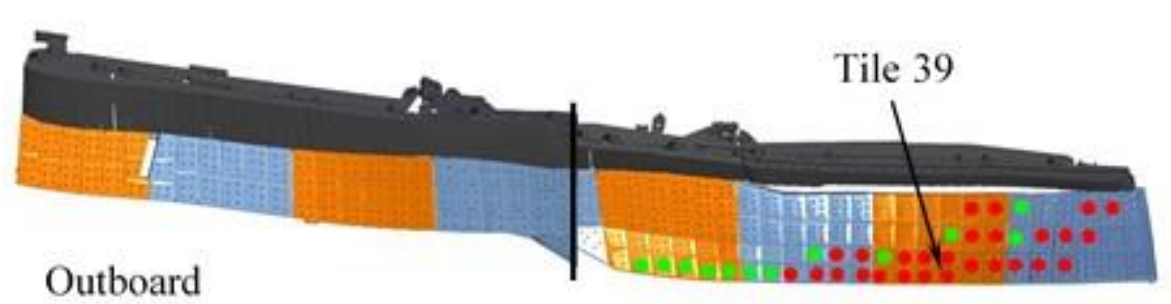

Figure 20. Configuration $6-\mathrm{P}_{\text {conv }}=8.0 \mathrm{MW}$ - Overloads. 
A similar behaviour (Figure 21) has been found for the "Low shear (mod.)" magnetic configurations (Id 7-9, as reported in Table 2). For this set of magnetic configurations, the highest heat flux has been predicted for configuration 7 (Figure 22), characterised by $\beta=1.20 \%$. Overloads spatial distribution for this configuration is shown in Figure 23 with the above mentioned colour code.

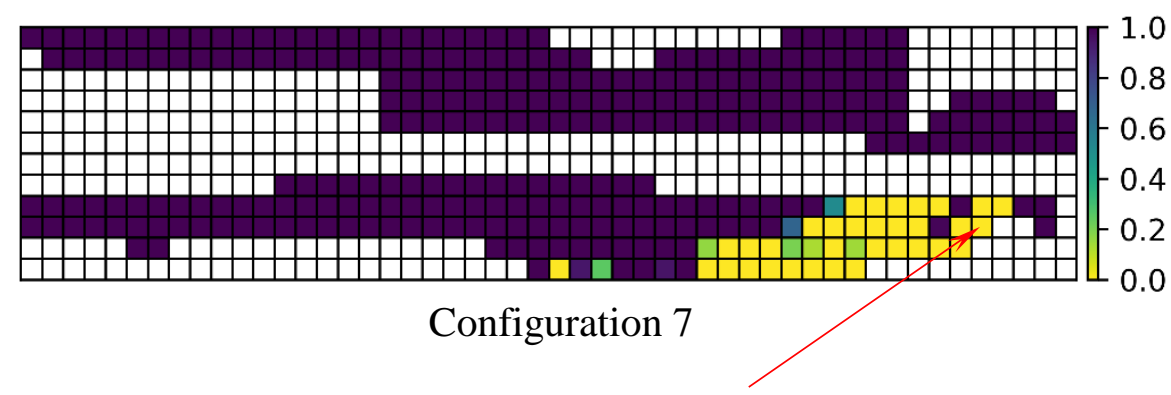

Min probability of safe operation - Tile 145

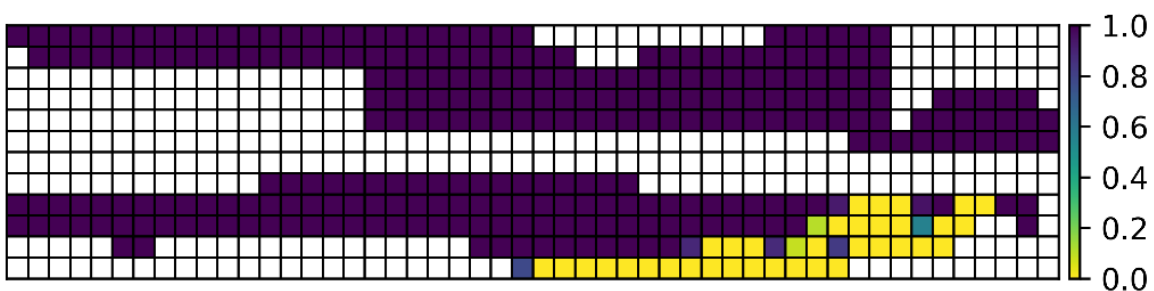

Configuration 8

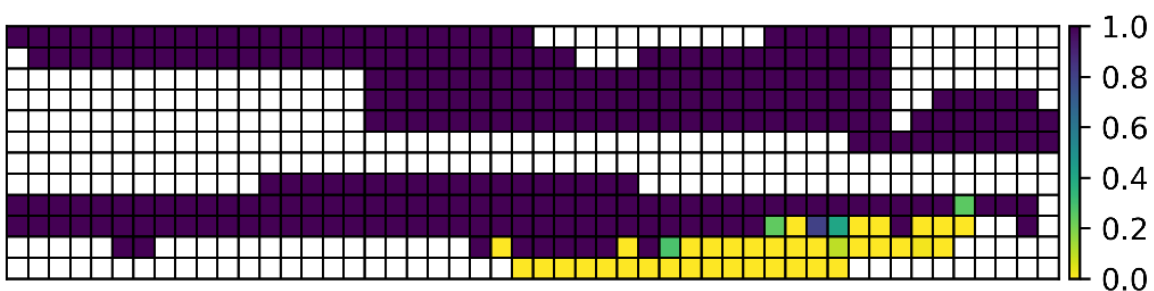

Configuration 9

Figure 21. Low shear (mod.) configurations $-\mathrm{P}_{\mathrm{conv}}=8.0 \mathrm{MW}-$ probability of safe operation.

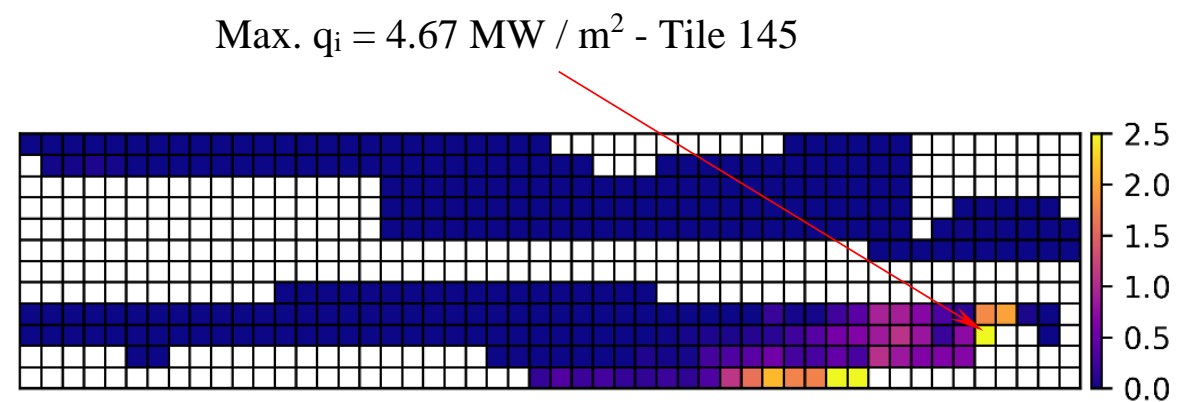

Figure 22. Configuration $7-\mathrm{P}_{\text {conv }}=8.0 \mathrm{MW}-\mathrm{q}_{\mathrm{i}}\left[\mathrm{MW} / \mathrm{m}^{2}\right]$. 


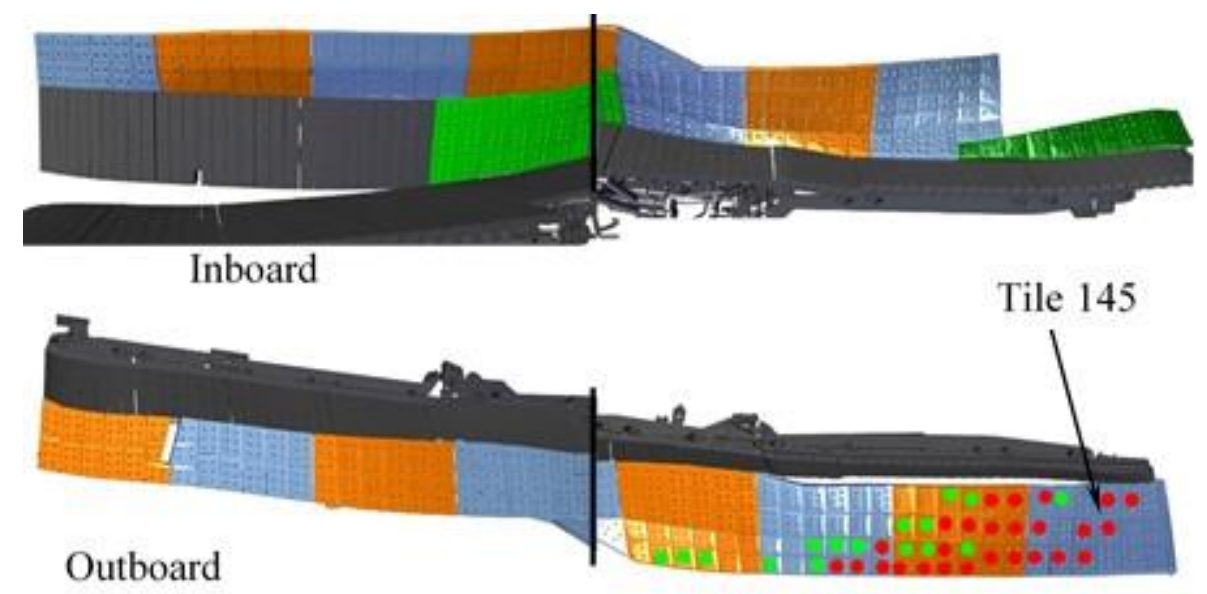

Figure 23. Configuration $7-\mathrm{P}_{\text {conv }}=8.0 \mathrm{MW}$ - Overloads.

Regarding "Outward shifted" iota magnetic configurations, (Id 10-12 in Table 2) the maximum $\beta$ (3.20\%, configuration 12) is the case where the overloaded area is the widest (Figure 24) and the maximum heat flux is achieved (Figure 25). For this configuration, the overloaded tiles are shown in Figure 26 with the usual colour code.

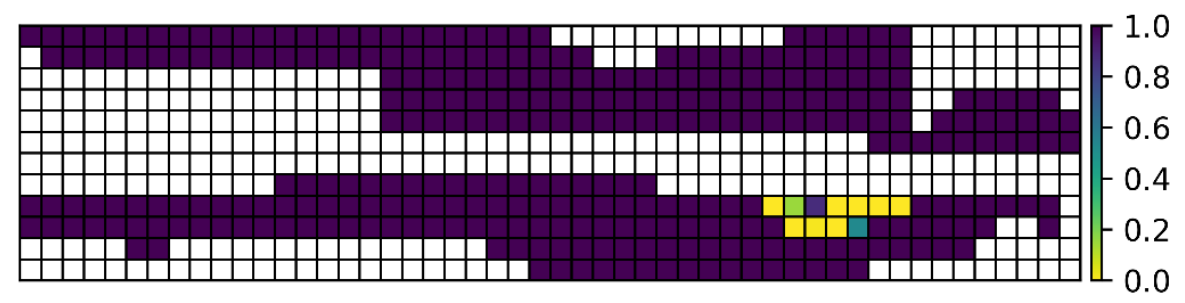

Configuration 10

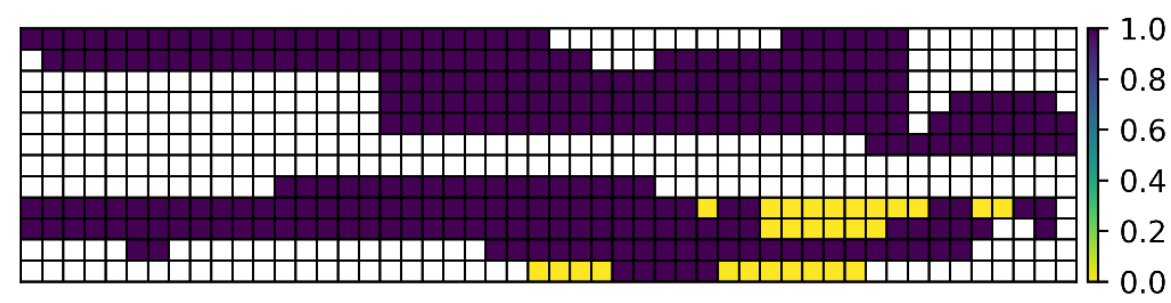

Configuration 11

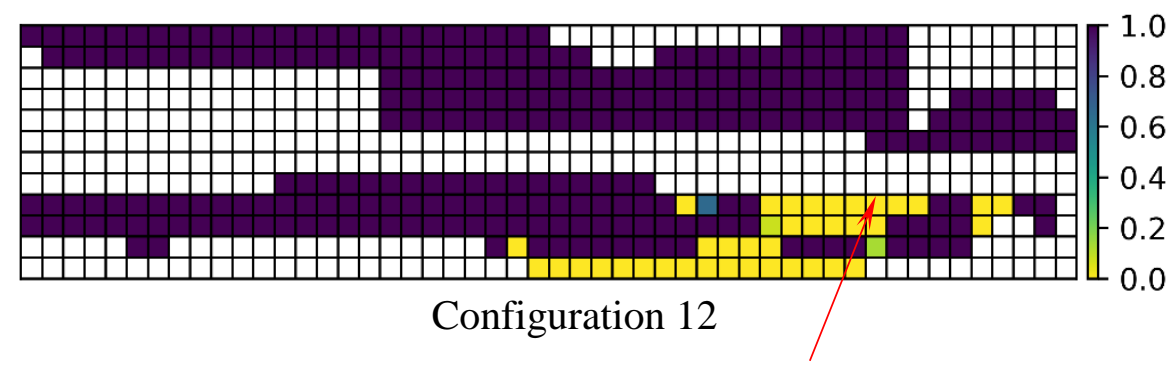

Min probability of safe operation - Tile 190

Figure 24. Outward shifted configurations $-\mathrm{P}_{\mathrm{conv}}=8.0 \mathrm{MW}-$ probability of safe operation. 


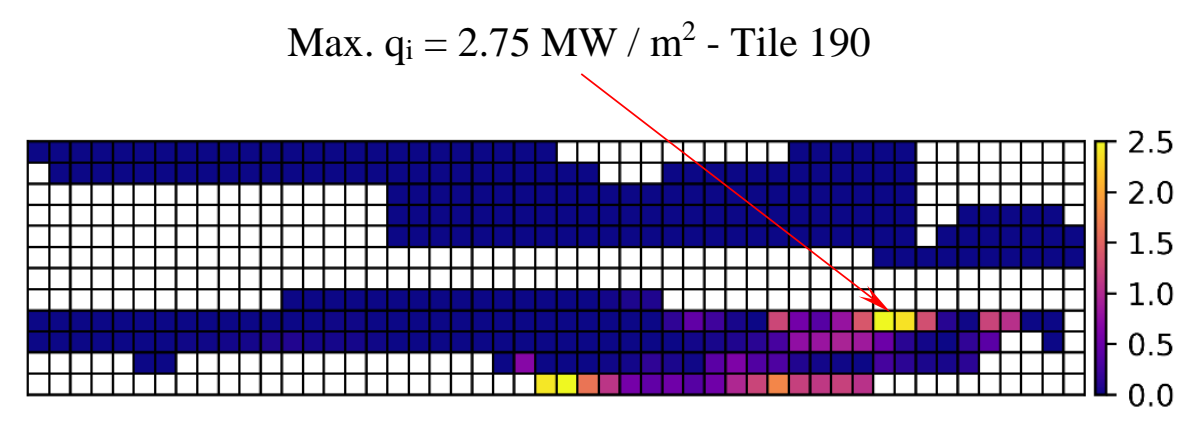

Figure 25. Configuration $12-\mathrm{P}_{\text {conv }}=8.0 \mathrm{MW}-\mathrm{q}_{\mathrm{i}}\left[\mathrm{MW} / \mathrm{m}^{2}\right]$.

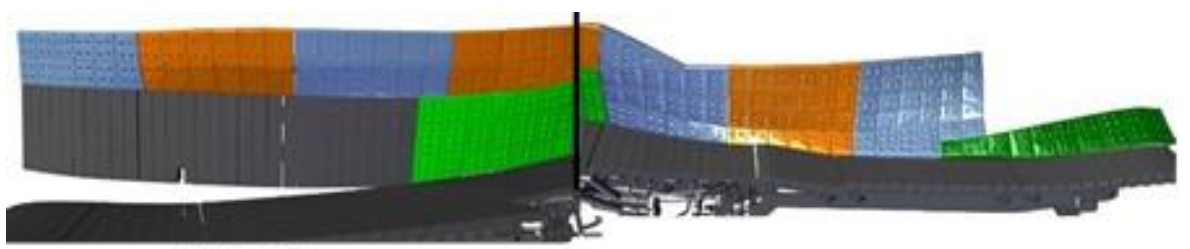

Inboard

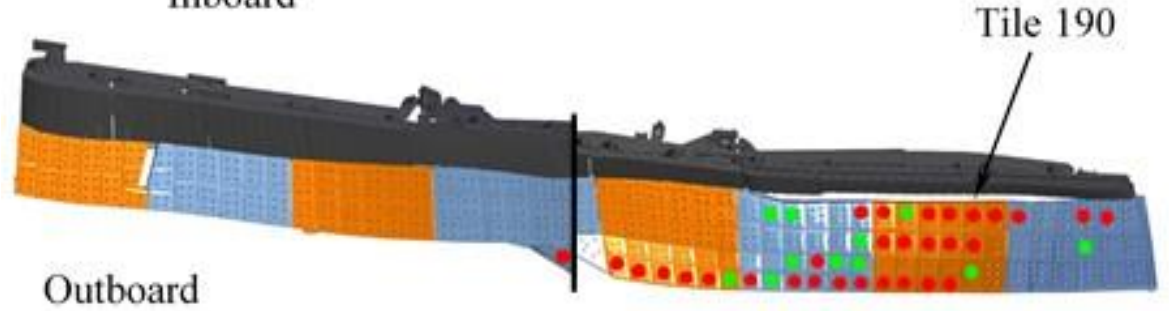

Figure 26. Configuration $12-\mathrm{P}_{\text {conv }}=8.0 \mathrm{MW}$ - Overloads.

As far as "Low iota" configurations (Id 13-15) are concerned, the highest $\beta$ value $(3.10 \%)$ causes the arising of a significant overloaded area. For this configuration (configuration 15), the obtained results are shown in Figure 27, Figure 28 and Figure 29.

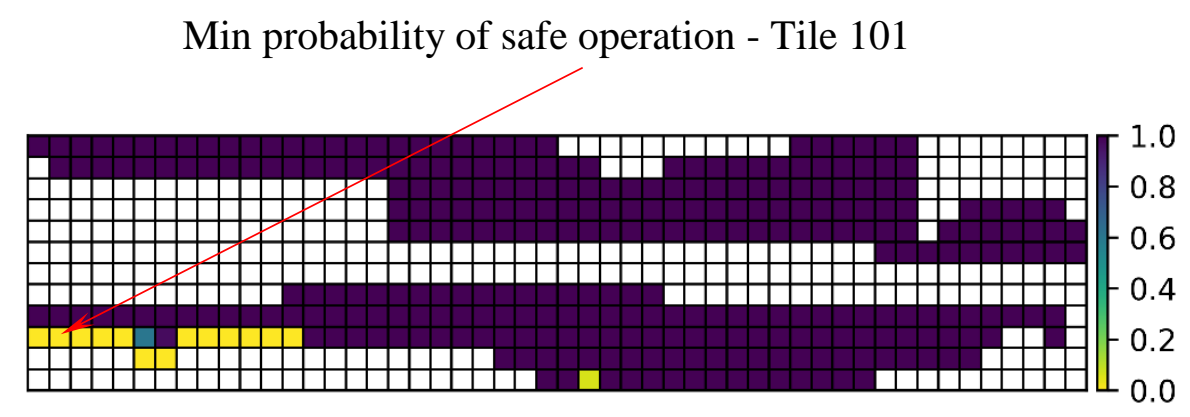

Figure 27. Configuration $15-\mathrm{P}_{\mathrm{conv}}=8.0 \mathrm{MW}-$ probability of safe operation. 


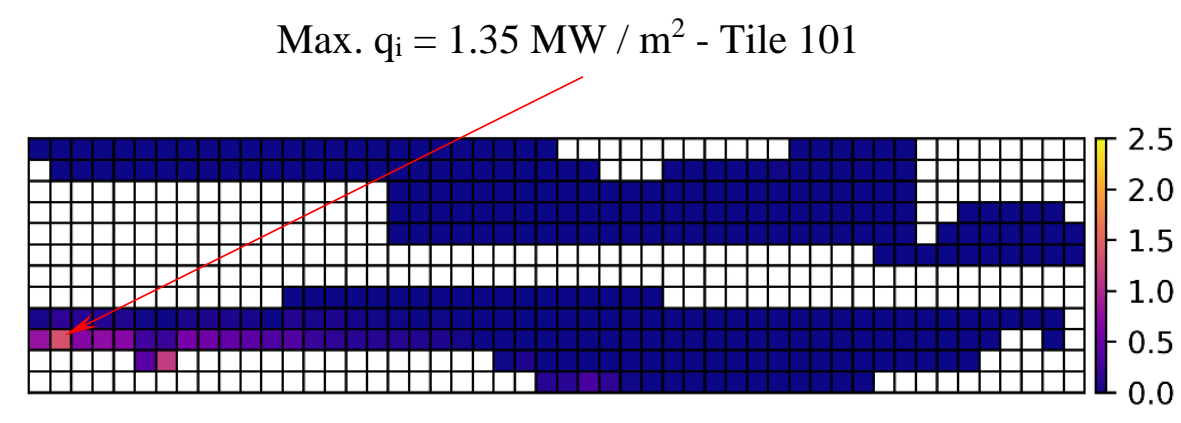

Figure 28. Configuration $15-\mathrm{P}_{\text {conv }}=8.0 \mathrm{MW}-\mathrm{q}_{\mathrm{i}}\left[\mathrm{MW} / \mathrm{m}^{2}\right]$.

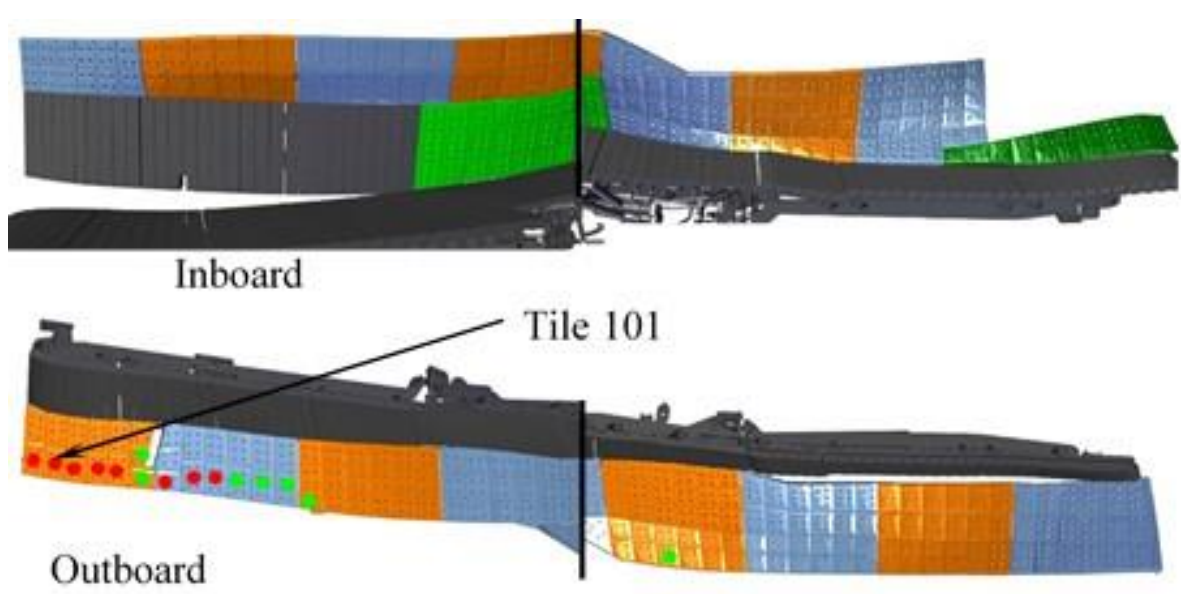

Figure 29. Configuration $15-\mathrm{P}_{\text {conv }}=8.0 \mathrm{MW}$ - Overloads.

Lastly, among the "High mirror" magnetic configurations (Id 16-18), the most critical results are predicted for configuration 17. It has to be noted that, in this set of magnetic configurations, overloads arise onto the inboard baffle panels (Figure 30, Figure 31 and Figure 32).

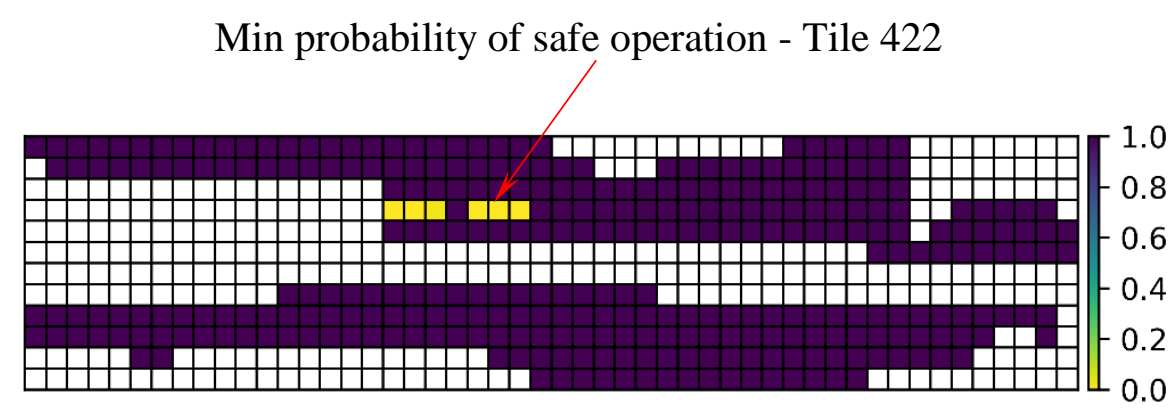

Figure 30. Configuration $17-\mathrm{P}_{\mathrm{conv}}=8.0 \mathrm{MW}$ - probability of safe operation. 


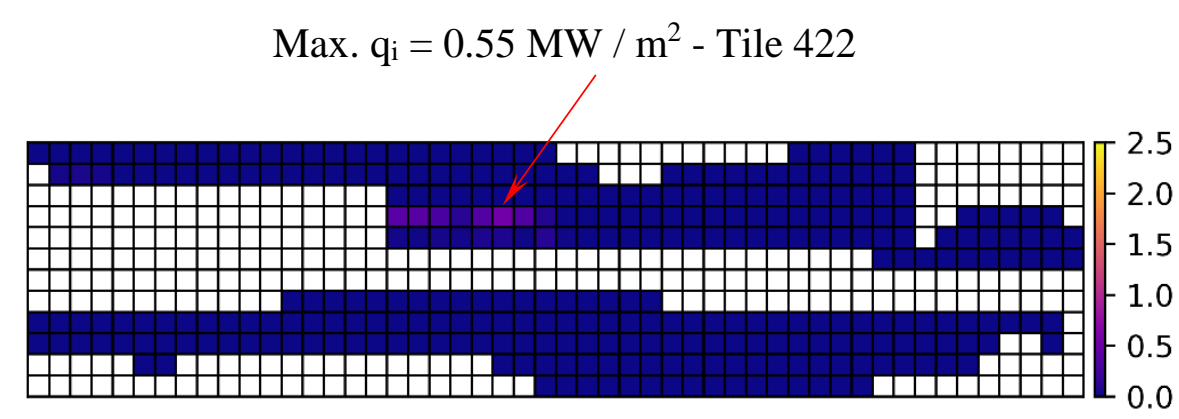

Figure 31. Configuration $17-\mathrm{P}_{\text {conv }}=8.0 \mathrm{MW}-\mathrm{q}_{\mathrm{i}}\left[\mathrm{MW} / \mathrm{m}^{2}\right]$.

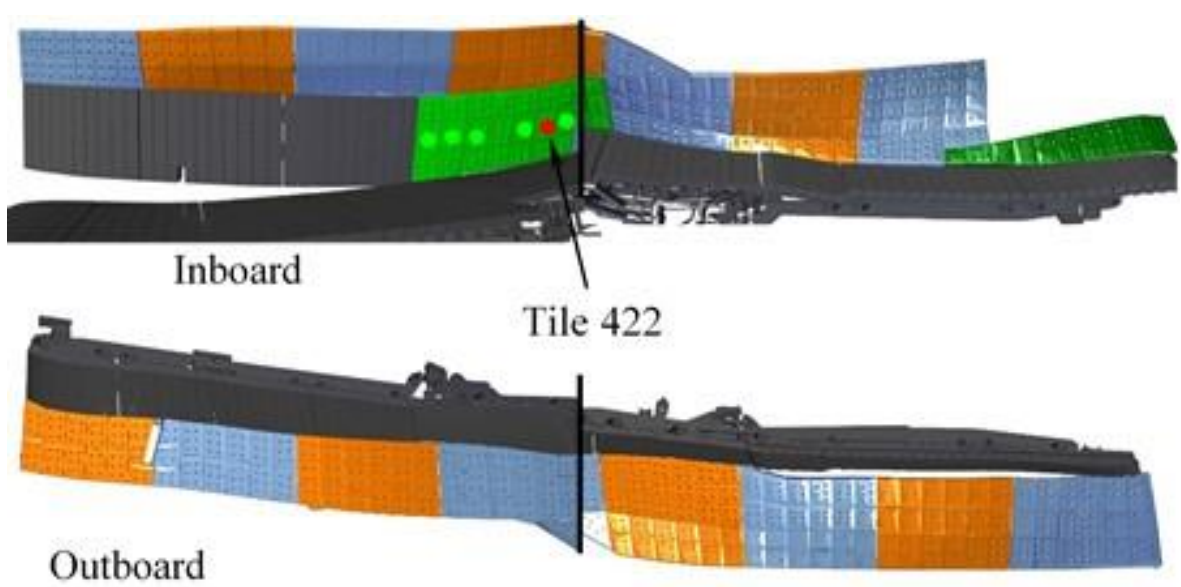

Figure 32. Configuration $17-\mathrm{P}_{\text {conv }}=8.0 \mathrm{MW}$ - Overloads.

No baffle overload has been predicted for the "High Iota" magnetic configurations, which are safe in all the conditions investigated.

In Table 6, a summary of the maximum heat flux predicted in all the overloaded configurations for $\mathrm{P}_{\text {conv }}=8.0 \mathrm{MW}$ and $\mathrm{q}_{\mathrm{d}, \mathrm{i}}=0.25 \mathrm{MW} / \mathrm{m}^{2}$ is reported.

Table 6. Baffle overloads summary $-\mathrm{P}_{\text {conv }}=8.0 \mathrm{MW}$ and $\mathrm{q}_{\mathrm{d}, \mathrm{i}}=0.25 \mathrm{MW} / \mathrm{m}^{2}$.

\begin{tabular}{ccccc}
\hline Id & 1 & $\beta$ & Max. $\mathrm{q}_{i}\left[\mathrm{MW} / \mathrm{m}^{2}\right]$ & Tile \\
\hline 2 & Standard & $2.00 \%$ & 0.24 & 228 \\
3 & Standard & $3.39 \%$ & 1.68 & 228 \\
4 & Low shear (orig.) & $1.00 \%$ & 1.42 & 145 \\
5 & Low shear (orig.) & $2.00 \%$ & 3.72 & 145 \\
6 & Low shear (orig.) & $3.10 \%$ & 3.78 & 39 \\
7 & Low shear (mod.) & $1.20 \%$ & 4.67 & 145
\end{tabular}




\begin{tabular}{cc|c|c|c}
8 & Low shear (mod.) & $2.50 \%$ & 4.66 & 39 \\
9 & Low shear (mod.) & $3.80 \%$ & 4.51 & 35 \\
10 & Outward shifted & $1.00 \%$ & 0.72 & 185 \\
11 & Outward shifted & $2.00 \%$ & 2.63 & 190 \\
12 & Outward shifted & $3.20 \%$ & 2.75 & 190 \\
13 & Low iota & $1.00 \%$ & 0.23 & 151 \\
15 & Low iota & $3.10 \%$ & 1.35 & 101 \\
16 & High mirror & $0.83 \%$ & 0.40 & 422 \\
17 & High mirror & $1.68 \%$ & 0.55 & 422 \\
18 & High mirror & $3.44 \%$ & 0.43 & 422 \\
\hline
\end{tabular}

Looking at the data reported in Table 6, it has to be noticed that in configurations 2 and 13 the maximum allowable heat flux is not actually overcome. Nevertheless, since the predicted value is very close to the limit of $0.25 \mathrm{MW} / \mathrm{m}^{2}$ (less than $10 \%$ different), even these configurations are considered as overloaded due to statistical reasons.

Finally, it can be deduced that at least 9 temperature sensors (i.e. thermocouples) have to be installed onto tiles 35, 39, 101, 145, 151, 190, 228 and 422 in order to detect occurring overload heat fluxes in all investigated configurations.

\section{Acknowledgments}

Authors want to thank M. Krause for providing the CAD views of the baffles and shields.

This work has been carried out within the framework of the EUROfusion Consortium and has received funding from the Euratom research and training programme 2014-2018 and 2019-2020 under grant agreement No 633053. The views and opinions expressed herein do not necessarily reflect those of the European Commission.

\section{References}

[1] T. Donné et al., European Research Roadmap to the Realisation of Fusion Energy, EUROfusion, 2018 (ISBN 978-3-00-061152-0).

[2] R. C. Wolf et al., Major results from the first plasma campaign of the Wendelstein 7-X stellarator, Nucl. Fusion 57 (10) 102020, 2017.

[3] T. Sunn Pedersen et al., Confirmation of the topology of the Wendelstein 7-X magnetic field to better than 1:100000, Nature Communications 7, 2016, p. 13493. issn: 2041-1723.

[4] T. Klinger et al., Performance and properties of the first plasmas of Wendelstein 7-X, Plasma Physics and Controlled Fusion 59.1, 2017. issn: 13616587. 
[5] A. Dinklage et al., Magnetic configuration effects on the Wendelstein 7-X stellarator, Nature Physics 14, 855-860, 2018.

[6] C. Beidler et al., Physics and Engineering Design for Wendelstein VII-X, Fusion Science and Technology 17.1, 1990, pp. 148-168.

[7] J. Nührenberg and R. Zille, Stable stellarators with medium $\beta$ and aspect ratio, Physics Letters A 114.3, 1986, pp. 129-132. issn: 03759601.

[8] T. Sunn Pedersen et al., Key results from the first plasma operation phase and outlook for future performance in Wendelstein 7-X, Physics of Plasmas 24.5, 2017. issn: 10897674.

[9] T. Sunn Pedersen et al., First results from divertor operation in Wendelstein 7-X, Plasma Phys. Control. Fusion 61 (2019) 014035.

[10] J. Geiger et al., Physics in the magnetic configuration space of W7-X, Plasma Phys. Control. Fusion 57 (2015) 014004.

[11] Y. Feng et al., Physics of island divertors as highlighted by the example of W7-AS, Nucl. Fusion 46 (2006) 807-819. (doi: 10.1088/0029-5515/46/8/006)

[12]H. Greuner et al., Structure of divertor for the optimised stellarator W7X, Fusion Technology 1994 - Proceedings of the $18^{\text {th }}$ Symposium on Fusion Technology, pp. 323-326, 1995.

[13]P. Grigull et al., First island divertor experiments on the W7-AS stellarator, Plasma Phys. Control. Fusion 43 (2001) A175-A193.

[14]A. Peacock et al., Progress in the design and development of a test divertor (TDU) for the start of W7-X operation, Fus. Eng. Des., Volume 84, Issues 7-11, June 2009, Pages 1475-1478.

[15]J. Boscary et al., Actively Water-Cooled Plasma Facing Components of the Wendelstein 7-X Stellarator, Fusion Science and Technology, 64:2, 263-268, 2013.

[16]B. Mendelevitch et al., Lessons learned from the design and fabrication of the baffles and heat shields of Wendelstein 7-X, Fus. Eng. Des., Volume 88, Issues 9-10, October 2013, Pages 16601663.

[17]A. Peacock et al., The procurement and testing of the stainless steel in-vessel panels of the Wendelstein 7-X Stellarator, Fus. Eng. Des., Volume 86, Issues 9-11, October 2011, Pages 17061709.

[18]G. Bongiovì et al., Preliminary structural assessment of the HELIAS 5-B breeding blanket, Fus. Eng. Des., Volume 146, Part A, September 2019, Pages 55-58.

[19]U. Fischer et al., Nuclear design issues of a stellarator fusion power plant with breeder blanket in comparison to tokamaks, paper presented at 27th IAEA Fusion Energy Conference (FEC 2018).

[20]G. Bongioví et al., Advancements in the HELIAS 5-B breeding blanket structural analysis, contribution at the $14^{\text {th }}$ International Symposium on Nuclear Fusion Technology, Budapest, 22-27 Septermber 2019.

[21]. G. Bongiovì et al., Progresses in the structural assessment of the central region of a HELIAS 5-B breeding blanket half sector, Fus. Eng. Des., Volume 159, 111620, October 2020. 
[22] Y. Gao et al., Understanding and potential methods to mitigate baffle overloads observed on W7X, Nucl. Fusion 55 (6) 063025, 2019.

[23] J. Fellinger et al., Overview of fatigue life assessment of baffles in Wendelstein 7-X, Fus. Eng. Des., Volume 136, Part A, November 2018, Pages 292-297.

[24] S. A. Bozhenkov et al., Service oriented architecture for scientific analysis at W7-X. An example of a field line tracer, Fus. Eng. Des., Volume 88, Issue 11, November 2013, Pages 2997-3006.

[25] J. Kisslinger et al., Magnetic Field and Coil Systems of the Modular Helias Configuration HS 5 10, Fusion Technology 1990 - Proceedings of the 16th Symposium on Fusion Technology, pp. 15201524, 1991.

[26]P. Sinha et al., Numerical studies of scrape-off layer connection length in Wendelstein 7-X, Nucl. Fusion 58 (2018) 016027.

[27] J. Kisslinger, Principles of the W7-X divertor, IPP technical report, 1-ACB-T0002.0, 2009.

[28]H. Hölbe, Access to edge scenarios for testing a scraper element in early operation phases of Wendelstein 7-X, Nucl. Fusion 56 (2016) 026015.

[29]D. Böckenhoff et al., Application of improved analysis of convective heat loads on plasma facing components to Wendelstein 7-X, 2019, Nucl. Fusion 59.8086031.

[30] S. P. Hirshman et al., Three-dimensional free boundary calculations using a spectral Green's function method, Fus. Eng. Des., Volume 43, Issue 1, December 1986, Pages 143-155.

[31] M. Drevlak et al., PIES free boundary stellarator equilibria with improved initial conditions, Nucl. Fusion 45 (2005) 731-740.

[32] J. Kisslinger et al., Correction possibilities of magnetic field errors in WENDELSTEIN 7-X, Fus. Eng. Des., Volume 74, Issues 1-4, November 2005, Pages 623-626.

[33] T. Andreeva et al., Tracking of the magnet system geometry during Wendelstein 7-X construction to achieve the designed magnetic field, Nucl. Fusion 55 (2015) 063025.

[34] S. A. Lazerson et al., Error fields in the Wendelsteinn7-X stellarator, Plasma Phys. Control. Fusion 60 (2018) 124002.

[35] S. A. Bozhenkov et al., Measurements and correction of the 1/1 error field in Wendelstein 7-X, Nucl. Fusion 59 (2019) 026004. 